\title{
The calyx of Held
}

\author{
Ralf Schneggenburger • Ian D. Forsythe
}

Received: 6 April 2006 / Accepted: 7 June 2006 / Published online: 8 August 2006

(C) Springer-Verlag 2006

\begin{abstract}
The calyx of Held is a large glutamatergic synapse in the mammalian auditory brainstem. By using brain slice preparations, direct patch-clamp recordings can be made from the nerve terminal and its postsynaptic target (principal neurons of the medial nucleus of the trapezoid body). Over the last decade, this preparation has been increasingly employed to investigate basic presynaptic mechanisms of transmission in the central nervous system. We review here the background to this preparation and summarise key findings concerning voltage-gated ion channels of the nerve terminal and the ionic mechanisms involved in exocytosis and modulation of transmitter release. The accessibility of this giant terminal has also permitted $\mathrm{Ca}^{2+}$-imaging and -uncaging studies combined with electrophysiological recording and capacitance measurements of exocytosis. Together, these studies convey the panopoly of presynaptic regulatory processes underlying the regulation of transmitter release, its modulatory control and short-term plasticity within one identified synaptic terminal.
\end{abstract}

Keywords Calyx of Held - Synaptic transmission . Plasticity · Synaptic vesicle · Exocytosis · Voltage-gated channel $\cdot$ Modulation $\cdot$ Metabotropic receptor

R. Schneggenburger $(\bowtie)$

Laboratory of Synaptic Mechanisms,

École Polytechnique Fédérale de Lausanne (EPFL),

Brain Mind Institute,

Bâtiment AAB, Station 15,

CH-1015 Lausanne, Switzerland

e-mail: ralf.schneggenburger@epfl.ch

I. D. Forsythe

Cellular \& Molecular Neuroscience Group,

MRC Toxicology Unit, University of Leicester,

Leicester LE1 9HN, UK

\section{A short history of the calyx of Held}

The size of a synapse is a significant technical constraint for electrophysiological recording. The large dimensions of some invertebrate synapses have been exploited to provide considerable insight into presynaptic function (Llinas et al. 1972; Augustine et al. 1985; Young and Keynes 2005). However, the progress of similar studies in vertebrates was long hampered by the technical difficulty of presynaptic recording from small nerve terminals. Over the last 50 years, a range of preparations have contributed to our understanding of presynaptic mechanisms, from the neuromuscular junction (Katz 1969) to chromaffin cells (Neher and Marty 1982), chick ciliary ganglion (Martin and Pilar 1963; Stanley and Goping 1991), neurohypophysial nerve terminals (Lemos and Nordmann 1986; Jackson et al. 1991) and synaptosomal preparations (Nicholls and Sihra 1986), to name just a few. Given the predominance of fast glutamatergic synapses in the mammalian central nervous system (CNS) and their pivotal role in information processing, the development of a preparation at which direct presynaptic patch-clamp recordings were feasible and at which glutamate was the neurotransmitter was desirable. One candidate was the hippocampal mossy fibre terminal, from which direct recordings have indeed been achieved (Geiger and Jonas 2000). Another approach has made use of anatomical evidence for two giant synapses in the auditory pathway, the endbulbs of Held and calyces of Held, respectively.

Both synapses are glutamatergic and form part of the relay pathway subserving sound-source localisation in the auditory brainstem (Fig. 1a). They owe their name to the German anatomist Hans Held, who working in Leipzig in the late 19th century, studied the central auditory pathways by the Golgi staining technique in cats (Held 
1893). Ramón y Cajal intensively studied these giant synapses by using Golgi material from several species (Ramón y Cajal 1972) and rendered the first highresolution images of calyces of Held at the lightmicroscopic level. Held also gave his name to another auditory giant synapse called the endbulb of Held, which is the primary afferent synapse onto the bushy cells of the anterior ventral cochlear nucleus (aVCN; Lorente de No 1981). Physiological characterisation and intra-axonal recording from axons in the trapezoid body (Fig. 1) of cats showed bushy cell projections to several ipsilateral and contralateral nuclei, with all axons giving rise to one or rarely two calyces in the contralateral medial nucleus of the trapezoid body (MNTB; Spirou et al. 1990; Kuwabara et al. 1991; Smith et al. 1991). Immunohistochemical evidence first suggested that the calyx of Held could be glutamatergic (Grandes and Streit 1989) and this was confirmed by in vitro current-clamp recordings in brain slices showing block of excitatory inputs by the glutamate receptor antagonist DNQX (Banks and Smith 1992). Whole-cell voltage-clamp from MNTB neurons showed dual component excitatory postsynaptic currents (EPSCs) with a fast time-course component mediated by $\alpha$-amino-3-5-methyl-4-isoxazolepropionic acid (AMPA) receptors and a slower time-course N-methyl-D-aspartate (NMDA) receptor-mediated current (Forsythe and Barnes-Davies 1993).

Direct recordings from the calyx of Held presynaptic terminal were subsequently achieved by using patch-clamp methods in an in vitro slice preparation of the rat brainstem (Forsythe 1994; Borst et al. 1995). Presynaptic recording from the endbulb of Held synapses in the aVCN has proven technically more difficult and, so far, has only been achieved in the chick (Sivaramakrishnan and Laurent 1995). The accessibility of the calyx of Held has since been used to investigate presynaptic ion channels, $\mathrm{Ca}^{2+}$ influx, transmitter release and its short-term modulation under direct voltage-clamp control of the presynaptic terminal. The calyx of Held has also become a model

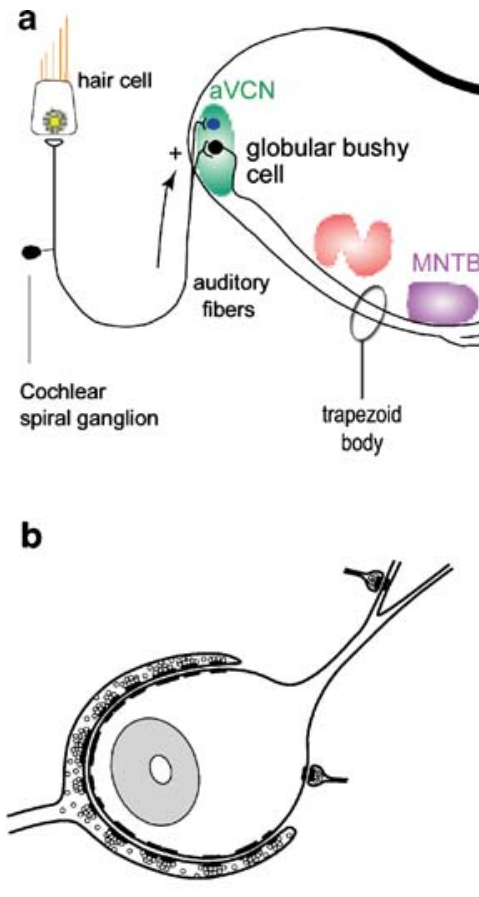

Fig. 1 The calyx of Held synapse in the auditory brainstem circuit. a Representation in the coronal plane of the brainstem auditory pathway and the calyx of Held synapse, which forms part of the auditory circuit at the level of the superior olivary complex (SOC). The calyx of Held is an excitatory glutamatergic synapse arising from globular bushy cells in the anterior ventral cochlear nucleus $(a V C N)$ onto a principal cell in the medial nucleus of the trapezoid body $(M N T B)$. The principal cells provide an inhibitory projection to other nuclei of the SOC such as the lateral superior olive (LSO). The bushy cells in the aVCN receive excitatory input from the auditory nerve fibres. The calyx of Held is thus a tertiary auditory synapse that rapidly relays information, providing the LSO and other nuclei with (inhibitory) information with regard to sound arriving at the contralateral ear. b Representation of a single calyx of

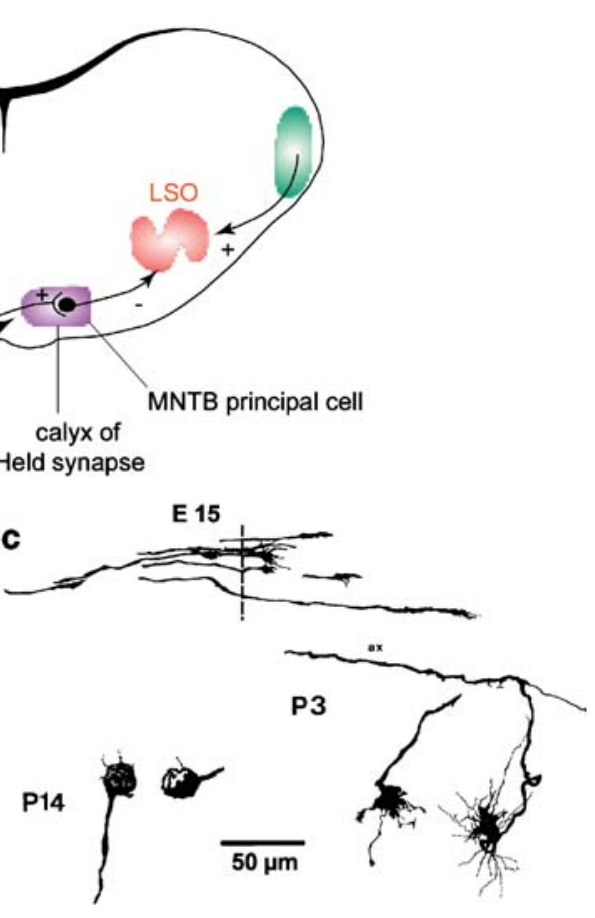

Held synapse onto a given single MNTB principal cell (modified, with permission from Elsevier, from Walmsley et al. 1998). The MNTB principal cells receive additional inhibitory and excitatory input through small bouton-like synapses but, in most cases, a given MNTB principal cell is thought to receive input from only one large calyx of Held. Thus, a one-to-one synaptic relationship exists between a given globular bushy cell and an MNTB principal cell. c Development of afferent fibres originating from the aVCN (reprinted, with permission of Wiley-Liss, from Kandler and Friauf 1993). The first fibres cross the midline approximately by embryonic day $15(E 15)$ and, at postnatal day 3 (P3), large calyceal synapses are formed and the one-to-one synaptic relationship is established. Later in development (P14), characteristic changes occur in the morphology of the calyx. (Data in this and subsequent figures are from rat) 
system for studying developmental changes of presynaptic function prior to hearing "onset" when the auditory canal opens (this occurs at around postnatal day 11 (P11) or P12 in rats and mice; Blatchley et al. 1987; Geal-Dor et al. 1993) and on towards maturation at around 20 days postnatally. The direct access of the nerve terminal to patch-clamp recording allows the manipulation of the intracellular biochemical environment, the introduction of $\mathrm{Ca}^{2+}$ indicators and light-sensitive $\mathrm{Ca}^{2+}$ chelators and the manipulation of the presynaptic $\mathrm{Ca}^{2+}$ concentration. In this review, we will briefly introduce the structure of the calyx of Held and then describe those research fields of synaptic transmission in which work on the calyx of Held has made important advances. Finally, we will discuss the advantages, limitations and future potential of the calyx of Held as a model presynaptic preparation.

\section{Function of the calyx of Held in the auditory brainstem circuitry}

The calyx of Held is thought to arise from globular bushy cells in the aVCN, which project onto principal neurons of the contralateral MNTB (see Fig. 1; Harrison and Irving 1966; Friauf and Ostwald 1988; Spirou et al. 1990; Kuwabara et al. 1991; Smith et al. 1991). It therefore forms a tertiary synapse in the auditory pathway. The MNTB principal cells provide inhibitory glycinergic projections to neighbouring nuclei in the superior olivary complex, including the lateral superior olive (LSO; see Fig. 1; Tollin 2003) and the medial superior olive (MSO; Banks and Smith 1992; Joris et al. 1998; Brand et al. 2002). The LSO and MSO are the first nuclei in which binaural information converges, with the calyx of Held/MNTB synapse forming a fast "inverting" relay, at which excitation originating from the contralateral cochlea is converted into inhibition to the ipsilateral auditory brainstem. The large size of the calyx of Held allows it to harbour hundreds of active zones (see below) and thus a single presynaptic action potential (AP) releases hundreds of quanta, generating a large EPSC that rapidly depolarises the MNTB neuron to threshold. Hence, the large size of the presynaptic terminal guarantees rapid signalling, preserving the timing information of the acoustic signal for processing by the binaural circuits underpinning sound localisation (Oertel 1999; Trussell 1999).

A single MNTB principal neuron receives input from only one calyx-type synapse, although multiple calyceal inputs are occasionally observed in $\sim 5 \%$ of principal neuron recordings in mice (Bergsman et al. 2004) and $\sim 20 \%$ of the afferent fibres give rise to two calyces on separate MNTB principal neurons (Kuwabara et al. 1991; Smith et al. 1991; Rodríguez-Contreras et al. 2006). In addition to the calyceal input, principal cells receive conventional excitatory synapses (Forsythe and Barnes-Davies 1993; Hamann et al. 2003) and inhibitory inputs (Banks and Smith 1992; Awatrami et al. 2004). The calyx of Held develops early, with trapezoid axons growing from the cochlear nucleus, crossing the midline by E15 and forming large precalyceal nerve endings by P3 (Fig. 1c; Kandler and Friauf 1993; see also Morest 1968; Hoffpauir et al. 2006).

\section{Morphology and ultrastructure of the calyx of Held}

A number of electron-microscopic (EM) studies have been conducted on calyces of Held (Lenn and Reese 1966; Nakajima 1971; Jean-Baptiste and Morest 1975; Sätzler et al. 2002; Taschenberger et al. 2002) and endbulbs of Held (Lenn and Reese 1966; Ryugo et al. 1996; Nicol and Walmsley 2002). They show that despite the large size of the nerve terminal (Fig. 2a), individual active zones of calyceal nerve endings in the MNTB and VCN are morphologically similar to those of conventional small nerve terminals (Fig. 2b). Calyceal terminals arise from a myelinated axon, which can be thick in cats $(5-10 \mu \mathrm{m}$; Rowland et al. 2000) but is thinner in rats $(<2 \mu \mathrm{m}$; Rodríguez-Contreras et al. 2006). Small synaptic vesicles (SSVs) accumulate at electron-dense contact sites, the active zones (Fig. 2b). Interestingly, calyceal SSVs are of slightly larger diameter $(\sim 45 \mathrm{~nm})$ than those contained in many small bouton-like hippocampal and cerebellar synapses, which are $\sim 35 \mathrm{~nm}$ in diameter (Schikorski and Stevens 1997; Xu-Friedman et al. 2001). An EM reconstruction of an entire calyx of Held from a P9 rat, by using serial ultrathin sections (Sätzler et al. 2002), has shown the presence of $\sim 550$ individual active zones, with an average nearest-neighbour separation of $\sim 0.6 \mu \mathrm{m}$. Numerous non-synaptic contact sites, named puncta adherentia (also observed by Jean-Baptiste and Morest 1975), have also been found. Synaptic contact sites (active zones) have an average surface area of $0.1 \mu \mathrm{m}^{2}$, similar to estimates for hippocampal and cerebellar excitatory synapses (Schikorski and Stevens 1997; XuFriedman et al. 2001) and contain an average of two morphologically docked vesicles (Sätzler et al. 2002). Another study has estimated that the extrapolated number of active zones increases from $\sim 300$ at P5 to $\sim 680$ at P14 (Taschenberger et al. 2002). The number of active zones corresponds well to the estimated number of functional active zones based on EPSC fluctuation analysis (Meyer et al. 2001; and see Fig. 5b). Thus, the calyx of Held can be seen as a vast "parallel" arrangement of hundreds of active zones, all activated by a single presynaptic AP.

Although the calyx of Held contains "conventional" active zones, there is some evidence for structural specialisations 
Fig. 2 Morphology and ultrastructure of the calyx of Held. a Electron micrograph of the calyx of Held from a P9 rat (yellow presynaptic calyx, blue postsynaptic MNTB principal neuron, red its nucleus, boxed area active zone). Bar $5 \mu \mathrm{m}$. Taken, with permission, from Sätzler et al. (2002); copyright 2002 by the Society for Neuroscience. b High resolution EM images of active zones within calyces of Held (green vesicles identified as morphologically docked). Left Two neighbouring active zones from a P5 rat. Right Single active zone in a P14 rat. Bars 200 nm. Reprinted, with permission from Elsevier, from Taschenberger et al. (2002)

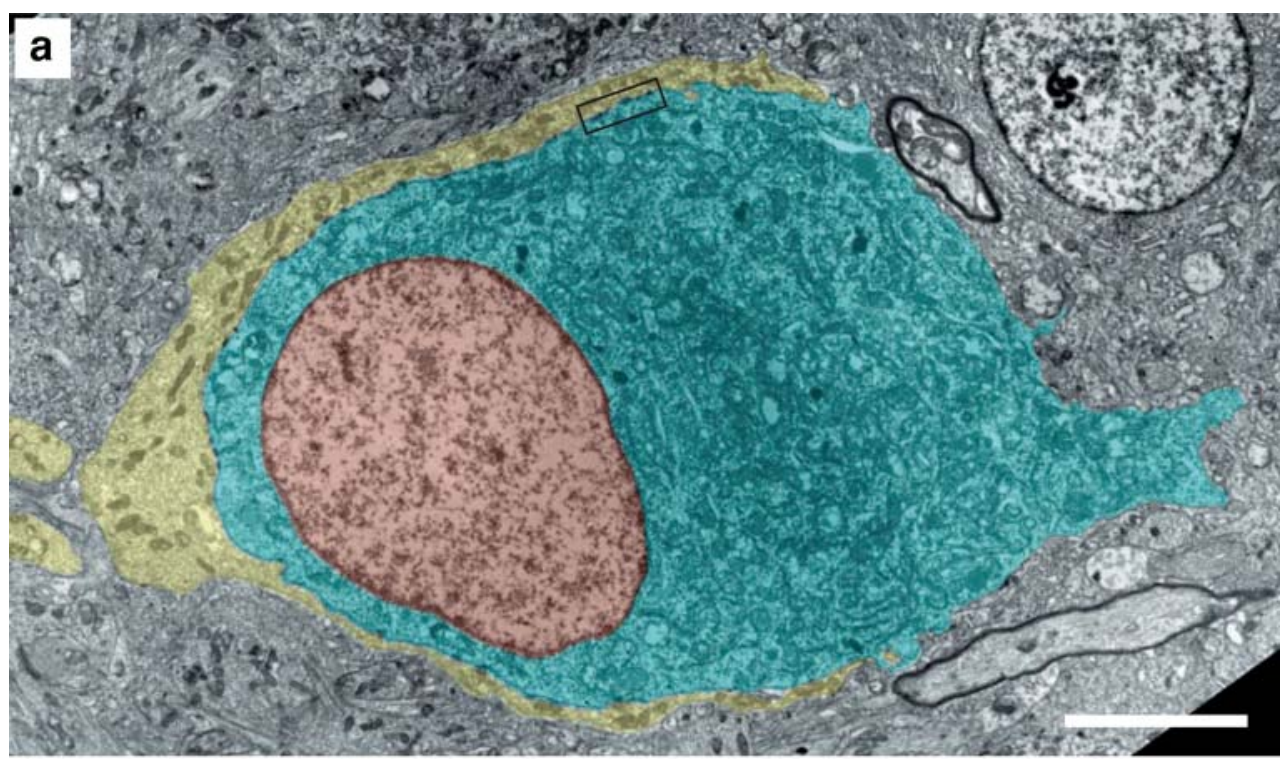

b

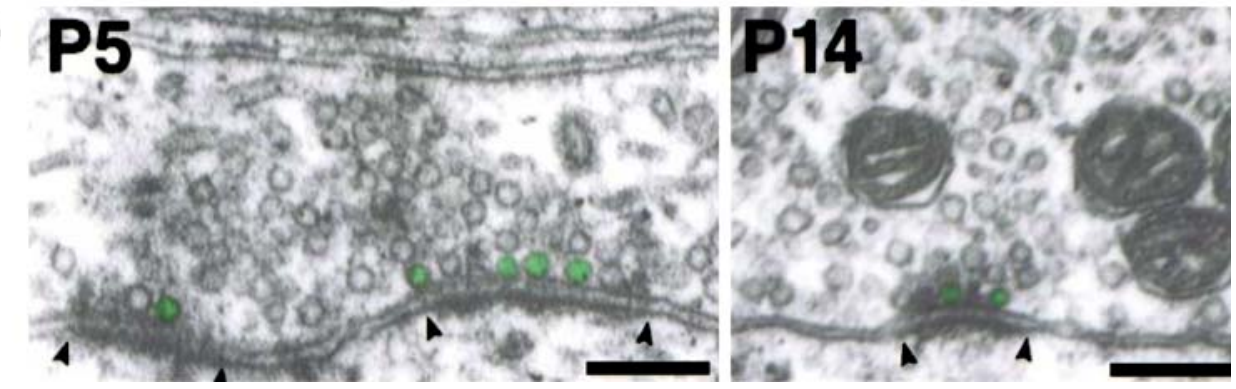

beyond mere size. Investigations of mature calyces by Rowland et al. (2000) in the cat have revealed that the nonsynaptic contact sites (puncta adherentia) are associated with tethered mitochondria within $200 \mathrm{~nm}$ of the membrane, a complex that they have called the "mitochondria-associated adherens complex" (MAC). Recently, Wimmer et al. (2006) have found, by using confocal fluorescence microscopy after virus-mediated over-expression of synaptic vesicle proteins (Wimmer et al. 2004), that vesicle clusters and active zones are organised in "donut"-like assemblies of $\sim 1 \mu \mathrm{m}$ in diameter. Electron microscopy has revealed that the "donuts" are comprised of 5-9 active zones clustered around the same number of mitochondria. Interestingly, "donuts" only appear during maturation of the calyx of Held after the opening of the auditory canal (at P11/12; Blatchley et al. 1987; Geal-Dor et al. 1993). The intricate arrangement of the release apparatus (vesicle clusters and active zones) and mitochondria might represent an optimal spatial arrangement for fast re-supply of ATP and for local $\mathrm{Ca}^{2+}$ sequestration into mitochondria (Billups and Forsythe 2002). This arrangement might be advantageous for sustaining high rates of transmitter release during the high frequency firing that occurs physiologically at the calyx of Held (Kopp-Scheinpflug et al. 2003).

\section{Presynaptic AP and ion channels of the calyx of Held}

Direct recording of presynaptic conductances at synaptic terminals in the mammalian CNS has so far only been achieved at three sites: the excitatory calyx of Held, the mossy fibre terminals (Geiger and Jonas 2000) and the cerebellar inhibitory pinceau (Southan and Robertson 1998). An example of a calyx of Held (filled with Lucifer yellow) viewed by differential interference contrast optics and then under fluorescence illumination is shown in Fig. 3a. Because of the continuity of the calyceal nerve terminal and its axon, whole-cell recording from the calyx will include currents arising from proximal parts of the axon, with the current and voltage responses of a terminal being influenced by the length of the intact axon. For instance, terminals with short axons fire a single AP on sustained depolarisation, whereas terminals with intact axons in excess of $150 \mu \mathrm{m}$ exhibit a sustained repetitive AP firing throughout the depolarisation (Dodson et al. 2003). Our objective here is to summarise the ionic conductances regulating excitability and AP generation at the calyx of Held.

Presynaptic resting membrane potentials (RMPs) at the calyx are around $-75 \mathrm{mV}$ (Forsythe 1994; Borst et al. 1995; 
Borst and Sakmann 1996), which is slightly more negative than the RMPs of the postsynaptic MNTB neuron at around $-65 \mathrm{mV}$. Upon afferent fibre stimulation, the calyx shows overshooting orthodromic presynaptic APs (Fig. 3b) reaching $+30 \mathrm{mV}$, with half-widths of $0.41 \mathrm{~ms}$ at $25^{\circ} \mathrm{C}$ (Dodson et al. 2003) and $0.26 \mathrm{~ms}$ at $36^{\circ} \mathrm{C}$ (Borst and Sakmann 1998b; Kushmerick et al. 2006). A developmental acceleration in the presynaptic AP time-course is also apparent, with halfwidths at P14 being less than half of those at P7 (Fig. 3c; Taschenberger and von Gersdorff 2000). As previously observed from intra-axonal recording of myelinated axons (Barrett and Barrett 1982), the calyx APs are accompanied by depolarising after-potentials (DAP) of around $10 \mathrm{mV}$ in amplitude (Borst et al. 1995; Dodson et al. 2003; see Fig. 3b). DAPs peak with latencies of around $5 \mathrm{~ms}$, last between 20 and $100 \mathrm{~ms}$ and are unaffected by blocking $\mathrm{Ca}^{2+}$ channels, by transmitter release or by increasing $\mathrm{Ca}^{2+}$ buffering, consistent with a postulated origin involving passive discharge of internodal capacitance (Barrett and Barrett 1982), although they may be further enhanced by the capacitive load of the terminal itself.

Presynaptic APs are blocked by tetrodotoxin (TTX; Forsythe 1994; Borst et al. 1995; Leao et al. 2005). In contrast to the ciliary ganglion (Martin and Pilar 1963), no evidence has been found for direct electrical transmission across gap junctions. The presynaptic axon is myelinated and hence AP propagation is via saltatory conduction with voltage-gated $\mathrm{Na}^{+}$channels located at nodes of Ranvier and $\mathrm{K}^{+}$channels at juxtaparanodal regions (Rasband and Shrager 2000). Voltage-gated $\mathrm{Na}^{+}$channel structure is similar to that of $\mathrm{Ca}^{2+}$ channels (Catterall et al. 2005). In the CNS, a developmental transition from expression of Nav1.2 to Nav1.6 occurs at maturation (Caldwell et al. 2000; Rios et al. 2003) in many areas of the brain. Immunohistochemical labelling shows that $\mathrm{Na}^{+}$channel density is low at the calyx, supporting the idea of passive AP propagation into the terminal but, by P12, Nav1.6 is located at a high density in the last segment of the axon (heminode, which is unmyelinated; Leao et al. 2005). This pattern of localisation differs from the situation in en-passant terminals, such as mossyfibre boutons, where a high density of voltage-gated $\mathrm{Na}^{+}$current has been found in outside-out patches from the terminal (Engel and Jonas 2005). With maturation up to P15, calyceal $\mathrm{Na}^{+}$currents increase in magnitude and show accelerating inactivation and recovery from inactivation (tau: $0.5 \mathrm{~ms}$ at $35^{\circ} \mathrm{C}$ ), contributing to increased afferent fibre excitability (Leao et al. 2005).

$K^{+}$channels Most alpha $(\alpha)$ subunits of $\mathrm{K}^{+}$channels have a structure analogous to one domain of voltage-gated $\mathrm{Na}^{+}$ channels; hence, four subunits must assemble to form a functional channel. Channels may be heterologous but are usually composed of subunits from within the same family, plus beta subunits and/or accessory proteins. With around $100 \mathrm{~K}^{+}$-channel subunit genes in more than 10 families, there is potential for huge diversity (Coetzee et al. 1999) and thus relating native channels to their recombinant counterparts is difficult, and it is worth providing a brief overview by way of introduction to presynaptic $\mathrm{K}^{+}$currents.

There are four families of mammalian voltage-gated $\mathrm{K}^{+}$ channels which can generate the classic "delayed rectifier" characteristics. The shaker-related Kv1 subunits (of which there are seven members) form channels activated by small depolarisations from RMP (10-40 mV, hence low voltageactivated) and are involved in regulating excitability and the threshold for AP firing. Kv1 channels may exhibit voltage-dependent inactivation through an N-terminal (N-type, ball and chain) mechanism (Aldrich 2001) but this depends on the subunit composition and/or presence of beta subunits. The two shab-related Kv2 subunits associate with many accessory subunits and generate a broad range of conductances. Kv2.1 channels are widely expressed but, as yet, little evidence exists for their immunolocalisation in the MNTB or synaptic terminals (R.E.W. Fyffe, personal communication). The four shaw-related Kv3 subunits are activated by larger depolarisations $(>50 \mathrm{mV}$, hence high voltage-activated). These voltages are only achieved during APs and Kv3 channels participate in repolarisation, particularly in fast-spiking interneurons (Rudy and McBain 2001). Finally, the three shal-related Kv4 subunits that generate transient inactivating subunits underlie A-type $\left(\mathrm{I}_{\mathrm{A}}\right)$ currents (Jerng et al. 2004). Like Kv1 channels, they are activated by small depolarisations but at resting potentials require membrane hyperpolarisation to remove steady-state inactivation. Other related $\mathrm{K}^{+}$channels, such as $\mathrm{Kv} 7$ (KCNQ; Delmas and Brown 2005) and twin-pore $\mathrm{K}^{+}$ channels (KCNK; Goldstein et al. 2001) are expressed in the auditory brainstem (Karschin et al. 2001; J. Johnston, A. Skrzypiec, M. Postlethwaite and I.D. Forsythe, in preparation) but will not be considered here.

The postsynaptic MNTB neuron expresses both low voltage-activated $\left(\mathrm{I}_{\mathrm{K}, \mathrm{LV}}\right)$ and high voltage-activated $\left(\mathrm{I}_{\mathrm{K}, \mathrm{HV}}\right)$ $\mathrm{K}^{+}$currents, which regulate firing threshold and AP repolarisation, respectively (Brew and Forsythe 1995; Dodson et al. 2002). $I_{K, L V}$ is blocked by the black mamba snake toxin, dendrotoxin-I (DTx-I), confirming mediation by Kv1 channels. Kv1 channels are located in cell bodies, dendrites, synaptic terminals (Wang et al. 1994) and juxtaparanodal regions of myelinated axons (Rasband and Shrager 2000). $\mathrm{I}_{\mathrm{K}, \mathrm{HV}}$ is mediated by Kv3 channels, which are generally associated with high frequency AP firing and mediate rapid AP repolarisation in many areas of the CNS (Rudy and McBain 2001), including the auditory brainstem, and are blocked by low (mM) concentrations of tetraethylammonium (Brew and Forsythe 1995; Wang and Kaczmarek 1998; for a review, see Kaczmarek et al. 2005). Activity- 
dependent changes in $\mathrm{Kv} 3$ channel activity are mediated by channel phosphorylation by casein kinase II (Macica and Kaczmarek 2001) and protein kinase C (PKC; Macica et al. 2003). In the MNTB, there is high basal phosphorylation at ser503 of $\mathrm{Kv} 3.1 \mathrm{~b}$ and this decreases the postsynaptic $\mathrm{K}^{+}$current amplitude. Exposure to moderate sound levels causes dephosphorylation and increases $\mathrm{I}_{\mathrm{K}, \mathrm{HV}}$ in the MNTB neuron (Song et al. 2005), thus improving the ability of MNTB principal cells to follow AP firing at high frequencies. Characterisation of the presynaptic $\mathrm{K}^{+}$currents is not complete but several studies have shown that, like the postsynaptic bushy cell and MNTB principal cell bodies, both low and high voltage-activated outward currents play a major role in regulating presynaptic AP firing.

$I_{K, L V}$ currents mediated by Kv1 channels Voltage clamp recordings have shown that calyces of Held possess a current activating over a low voltage range ( -60 to $-30 \mathrm{mV}$, Fig. 3e,f, closed symbols). These currents were blocked by DTx-I confirming mediation by Kv1 channels, and by tityustoxin $\mathrm{K} \alpha$, which is specific for channels containing Kv1.2 subunits, but were less sensitive to dendrotoxin-K, which blocks Kv1.1-containing channels (Dodson et al. 2002, 2003). Immunohistochemistry has confirmed that Kv1.2 subunits are located in the axon (see Fig. $3 \mathrm{~g}$ ) immediately adjacent to, but excluded from, the terminal itself. Thus, Kv1.2 localisation seems to overlap with the Nav1.6 location (Leao et al. 2005), compatible with a role in regulating threshold excitability.

Blockade of presynaptic Kv1 channels has no effect on AP halfwidth (Dodson et al. 2003) or on evoked transmitter release (Brew and Forsythe 1995) from a single AP but blockade increases DAP amplitude, which then elicits additional aberrant APs during the DAP. These results suggest that presynaptic Kv1 functions to shunt and to suppress terminal hyperexcitability and so minimises AP "reflection". Reflection arises because the duration of the DAP outlasts the $\mathrm{Na}^{+}$-channel refractory period, thus generating an antidromic AP under certain conditions (Dodson et al. 2003). Of note, Kv1 currents of the calyx of Held show little inactivation (Forsythe 1994; Dodson et al. 2003) and the calyx exhibits no short-term plasticity attributable to $\mathrm{Kv} 1$ channels. However, inactivating $\mathrm{K}^{+}$ currents do contribute to AP repolarisation at mossy fibre terminals (Geiger and Jonas 2000) and neurohypophysial terminals (Jackson et al. 1991; Thorn et al. 1991), where accumulation of inactivation during AP trains increases AP duration and $\mathrm{Ca}^{2+}$ influx and causes short-term facilitation of transmitter release.

$I_{K, H V}$ currents mediated by Kv3 channels Early recordings from the calyx have demonstrated that calyceal high voltage-activated outward $\mathrm{K}^{+}$currents are blocked by
Fig. 3 Presynaptic patch-clamp recordings from the calyx of Held: the nerve terminal action potential (AP) and voltage-gated $\mathrm{K}^{+}$ currents. a Nomarski image (differential interference contrast) of a single MNTB neuron with surrounding calyx (arrows). Presynaptic recording from this terminal was confirmed by labelling with Lucifer yellow from the patch pipette. Scale Neuronal diameter: $18 \mu \mathrm{m}$. b An orthodromic presynaptic AP followed by a depolarising after-potential $(D A P)$. Modified, with permission, from Borst et al. (1995). c Normalised presynaptic APs at three different postnatal developmental stages. The presynaptic AP is brief at P7 (half-width: $\sim 0.5 \mathrm{~ms}$ ) but becomes even briefer with further postnatal development. Modified, with permission, from Taschenberger and von Gersdorff (2000); copyright 2000 by the Society for Neuroscience. d Paired pre- and postsynaptic recording. Application of $1 \mathrm{mM}$ tetraethylammonium (TEA; blocks the highvoltage-activated $\mathrm{K}^{+}$current) increases AP duration (Pre) and increases transmitter release (EPSC). Taken, with permission, from Ishikawa et al. (2003); copyright 2003 by the Society for Neuroscience. e Outward $\mathrm{K}^{+}$currents of the calyx of Held generated on depolarisations from a holding potential of $-70 \mathrm{mV}$. Current traces are shown for voltage steps from -70 to $-5 \mathrm{mV}$, under control conditions in the presence of tetrodotoxin (top) and following application of tityustoxin-K $\alpha(100 \mathrm{nM}, T s T x-K \alpha, \mathrm{Kv} 1.2$ antagonist). The current amplitudes observed with steps to $-40 \mathrm{mV}$ (which largely correspond to the low-voltage-activated $\mathrm{K}^{+}$current, $\mathrm{I}_{\mathrm{K}, \mathrm{LV}}$ ) are indicated by filled black bar (left). f Current-voltage relationship of outward $\mathrm{K}^{+}$currents plotted at the time indicated by filled and open symbols in e. Note that TsTX-K $\alpha$ blocks all outward current at voltages up to $-30 \mathrm{mV}$. Taken, with permission, from Dodson et al. (2003). g Immunolocalisation of $\mathrm{Kv} 3.1 \mathrm{~b}$ and $\mathrm{Kv} 1.2$ subunits in the calyx (left, red) and the last $2 \mu \mathrm{m}$ of the axon (arrow). Kv1.2 subunits are not located in the calyx but are present in the last portion of the axon (centre, green). The overlay (right) shows that Kv3 and Kv1 channels are located in distinct compartments (stars, daggers). Bar $10 \mu \mathrm{m}$. Taken, with permission, from Dodson et al. (2003)

micromolar concentrations of 4-aminopyridine (Forsythe 1994). Low millimolar (1-3 $\mathrm{mM})$ concentrations of tetraethylammonium (which blocks Kv3 currents) increase AP duration (Wang and Kaczmarek 1998) and transmitter release (Ishikawa et al. 2003; Fig. 3d). Immunohistochemical studies at the light-microscopic level show that Kv3 subunits are absent from the heminode and so do not overlap with Kv1 or Nav1.6 channels (Dodson et al. 2003; Fig. 3g). Intriguingly, in EM studies, little or no Kv3.1b immunostaining has been observed on the release face but is concentrated on the non-release face of the synapse (Elezgarai et al. 2003). The reasons for this are unknown since, from a biophysical perspective, their location on one synaptic face or another would have little impact on their ability to repolarise presynaptic APs. One rationale, given that the calyx can occupy over $60 \%$ of the postsynaptic soma surface, is that accumulation of $\mathrm{K}^{+}$in the small volume of the synaptic cleft would have a dramatic impact on pre- and postsynaptic membrane potential and so, by locating these channels on the non-release face, secondary depolarisation of the pre- and postsynaptic membrane potentials is probably minimised; however, the mechanism of this localisation or exclusion from the release face is unknown. Given the broad distribution of phosphorylated$\mathrm{Kv} 3.1 \mathrm{~b}$ in both postsynaptic and presynaptic compartments 


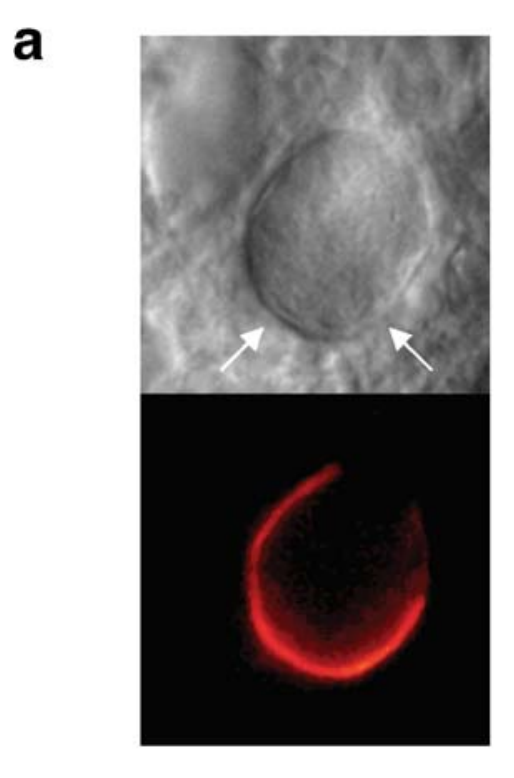

b

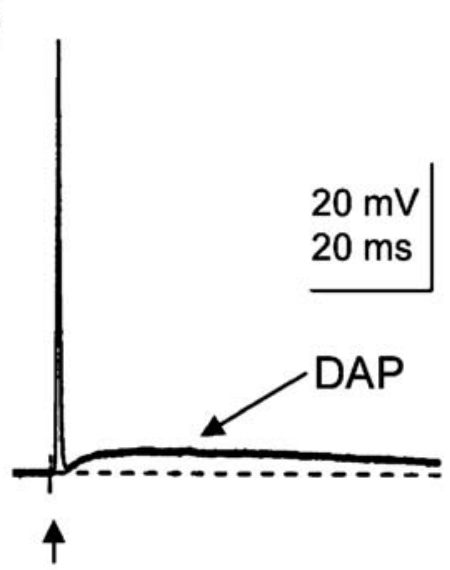

e
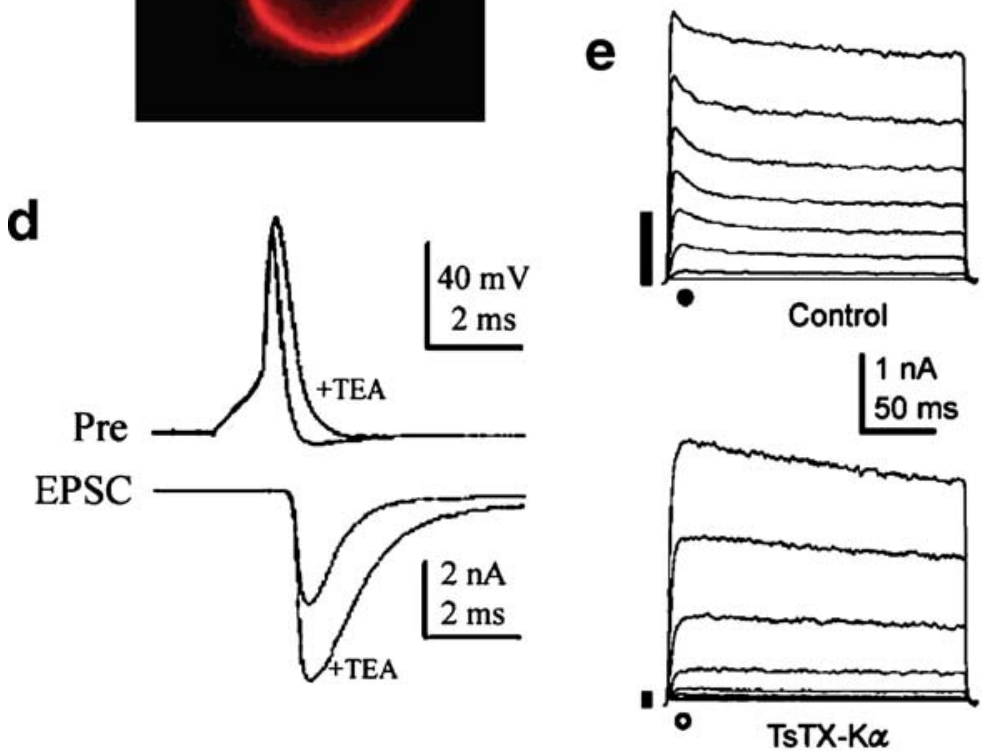

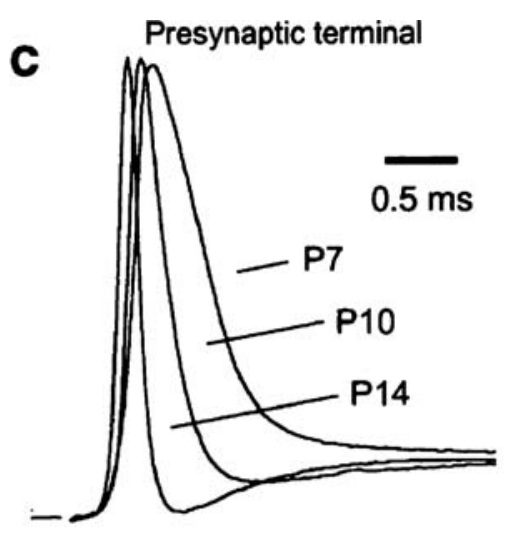

f

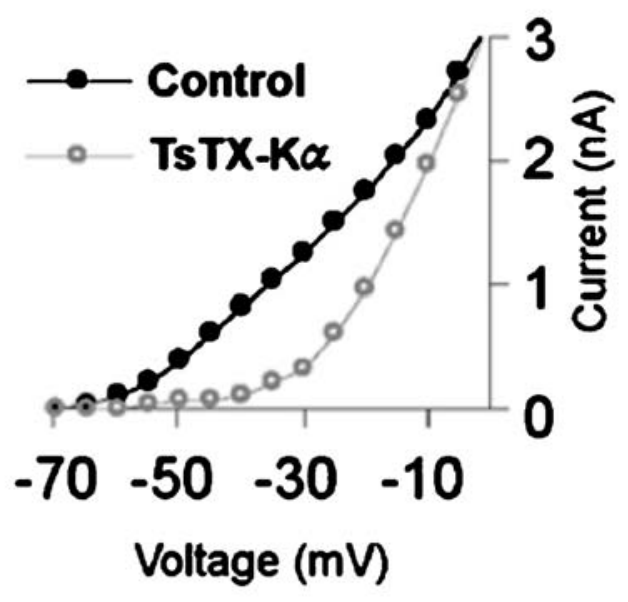

g

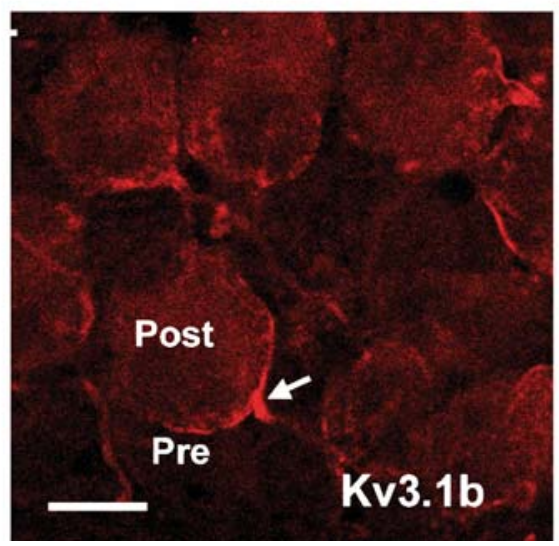

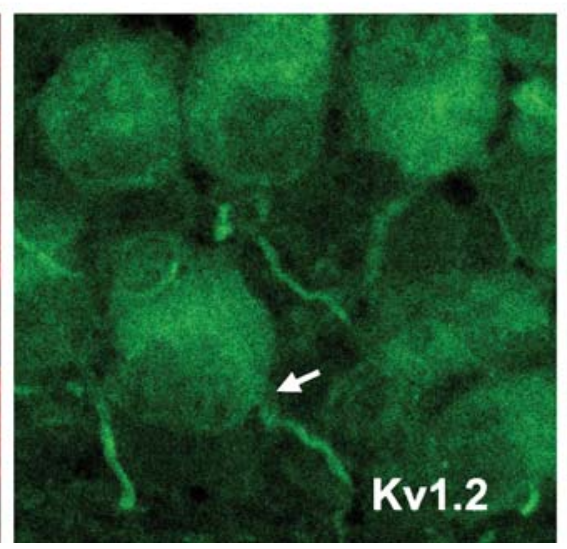

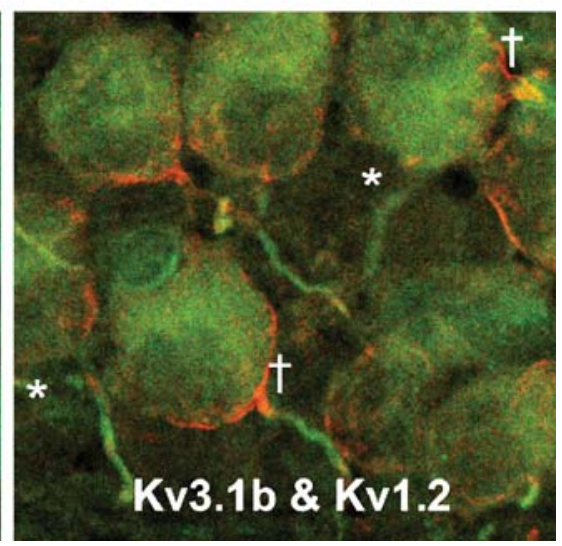

of the MNTB (Song et al. 2005), Kv3.1 modulation probably also occurs in the presynaptic terminal, but this has yet to be directly demonstrated.

$I_{H}$ currents As yet, little information has been obtained regarding $\mathrm{K}^{+}$channels responsible for setting RMPs in the
MNTB, but there is good evidence for the participation of an $I_{K, L V}$ and $I_{H}$ in octopus cells (Bal and Oertel 2001). Hyperpolarisation-activated non-specific cation currents, known as $\mathrm{I}_{\mathrm{H}}$, are mediated by $\mathrm{HCN}$ subunits and are permeable to $\mathrm{K}^{+}$and $\mathrm{Na}^{+}$(their reversal potential is around $-30 \mathrm{mV}$ ). They have relatively slow kinetics but are active 
at RMPs and are broadly expressed in the CNS (Santoro et al. 2000), being associated with oscillatory rhythm (Hu et al. 2002) and the control of dendrite excitability (Day et al. 2005). $I_{H}$ currents are present in the calyx of Held and the postsynaptic MNTB neuron (Banks et al. 1993; Cuttle et al. 2001). HCN1 and HCN2 subunits are expressed in specific neuronal patterns in various auditory brainstem nuclei (Koch et al. 2004). $I_{H}$ localised in presynaptic terminals can influence exocytosis at the crustacean NMJ (Beaumont and Zucker 2000) but, although initial studies have suggested similar effects in the hippocampus (Mellor et al. 2002), this has not been confirmed (Chevaleyre and Castillo 2002) and, at the calyx of Held, the blocking of $\mathrm{I}_{\mathrm{H}}$ does not modulate transmitter release (Cuttle et al. 2001). $I_{H}$ is also present at inhibitory synaptic terminals of cerebellar basket cells (Southan et al. 2000) where the blocking of $\mathrm{I}_{\mathrm{H}}$ (with ZD7288) increases the frequency of spontaneous inhibitory postsynaptic currents. $\mathrm{I}_{\mathrm{H}}$ is modulated by intracellular cAMP at both the postsynaptic MNTB neuron (Banks et al. 1993) and the presynaptic terminal (Cuttle et al. 2001) and so could contribute to activitydependent modulation of the presynaptic RMP, in concert with other low voltage-activated currents and leak channels.

$\mathrm{Ca}^{2+}$-activated $\mathrm{K}^{+}$channels There is good evidence that large conductance (BK) $\mathrm{Ca}^{2+}$-activated $\mathrm{K}^{+}$channels (generated by slo1 subunits) are widely expressed and influence transmitter release at the amphibian (Robitaille et al. 1993) and mammalian (Katz et al. 1995) neuromuscular junctions. Recent immunohistochemical studies have shown that slo1 is present in axons and terminals associated with glutamatergic synapses (Misonou et al. 2006). Pharmacological studies have shown that the BK antagonist iberiotoxin blocks a slow current in the calyx of Held (Ishikawa et al. 2003) and another study has noted a $\mathrm{K}^{+}$current activated by $\mathrm{Ca}^{2+}$ uncaging in the calyx of Held; this current is suppressed by tetraethylammonium (Wölfel and Schneggenburger 2003), which also blocks BK channels. However, further characterisation is required to understand the contribution of $\mathrm{Ca}^{2+}$-activated $\mathrm{K}^{+}$ channels to the regulation of transmitter release. In situ hybridisation and immunohistochemical data suggest that the related $\mathrm{Na}^{+}$-dependent $\mathrm{K}^{+}$channels, Slick and Slack (Bhattacharjee and Kaczmarek 2005), are expressed in the MNTB; their function is currently being assessed.

\section{Calcium channels at the calyx of Held}

Presynaptic $\mathrm{Ca}^{2+}$ channels have received considerable attention, since the calyx of Held preparation offers the means to study the presynaptic $\mathrm{Ca}^{2+}$ channels involved in triggering exocytosis at a glutamatergic synapse directly. Whole- terminal recordings under conditions suitable for blocking voltage-gated $\mathrm{Na}^{+}$and $\mathrm{K}^{+}$channels show peak inward $\mathrm{Ca}^{2+}$ currents of between 1-2 nA with $2 \mathrm{mM}\left[\mathrm{Ca}^{2+}\right]_{\mathrm{o}}$ (Borst et al. 1995; Borst and Sakmann 1996, 1998b; Forsythe et al. 1998; see Fig. 4a). Patch-clamp and immunohistochemical studies in young rats prior to the opening of the auditory canal (P10) have revealed that N-, R- and P-type $\mathrm{Ca}^{2+}$ channels contribute to the voltage-dependent $\mathrm{Ca}^{2+}$ influx (Wu et al. 1999). However, a shift in the balance of the presynaptic subunits occurs so that, from around $\mathrm{P} 10$, the $\mathrm{Ca}^{2+}$ currents triggering exocytosis are sensitive only to $\omega$ - agatoxin-IVA (Forsythe et al. 1998), indicating the dominance of the P-type $\mathrm{Ca}^{2+}$ channel formed by $\mathrm{CaV} 2.1$ subunits. The sensitivity of the presynaptic $\mathrm{Ca}^{2+}$ current to $\omega$-agatoxin IVA is shown in Fig. 4c. Developmental studies have clearly demonstrated that the switch from mixed N- and P- to P-type channels takes place at $\sim \mathrm{P} 10 / 11$ (Iwasaki and Takahashi 1998; Iwasaki et al. 2000). Although most studies have used voltage steps to evoke $\mathrm{Ca}^{2+}$ currents, Borst and Sakmann (1998b) have studied the activation of $\mathrm{Ca}^{2+}$ current during a presynaptic AP with two electrode voltage clamps and have shown that the peak inward $\mathrm{Ca}^{2+}$ current occurs shortly after the AP peak (Fig. 4d). A recent study of transmission efficacy during synapse development has revealed that acceleration of the presynaptic AP time-course decreases $\mathrm{Ca}^{2+}$ influx, whereas EPSC amplitude increases during maturation in mice, implying considerable enhancement in coupling efficacy during calyx of Held development (Yang and Wang 2006).

The presynaptic P-type $\mathrm{Ca}^{2+}$ channel shows the classical bell-shaped current/voltage curve (Fig. 4b) with little current at voltages negative to $-40 \mathrm{mV}$ and peak inward currents between $-20 \mathrm{mV}$ and $0 \mathrm{mV}$. The terminal does not possess any transient ("T-type") $\mathrm{Ca}^{2+}$ currents as can be seen by contrasting the $\mathrm{Ca}^{2+}$ currents evoked in a bushy cell body (which shows a clear T-type $\mathrm{Ca}^{2+}$ current) with the same voltage protocols delivered to a calyceal terminal (Fig. 4e, lower traces). The presynaptic P-type current is subject to several activity-dependent modulations. A form of $\mathrm{Ca}^{2+}$-dependent inactivation (Forsythe et al. 1998) can be seen from the initial decay of the current in the largest $(-15 \mathrm{mV}$ step) current trace in Fig. 4a. The inactivation depends on the presence of extracellular $\mathrm{Ca}^{2+}$ and, by analogy with the modulation of recombinant $\mathrm{P} / \mathrm{Q} \mathrm{Ca}^{2+}$ channels (DeMaria et al. 2001), this could be mediated by $\mathrm{Ca}^{2+} /$ calmodulin binding. $\mathrm{Ca}^{2+}$-current inactivation contributes to synaptic depression following prolonged highfrequency activity (Forsythe et al. 1998) and during the onset of repetitive stimulation ( $\mathrm{Xu}$ and $\mathrm{Wu}$ 2005). At short intervals, a short-term $\mathrm{Ca}^{2+}$-dependent facilitation lasting up to $100 \mathrm{~ms}$ occurs, which is distinct from the voltage-dependent relief of G-protein inhibition (Borst and Sakmann 1998a; Cuttle et al. 1998) and is mediated 

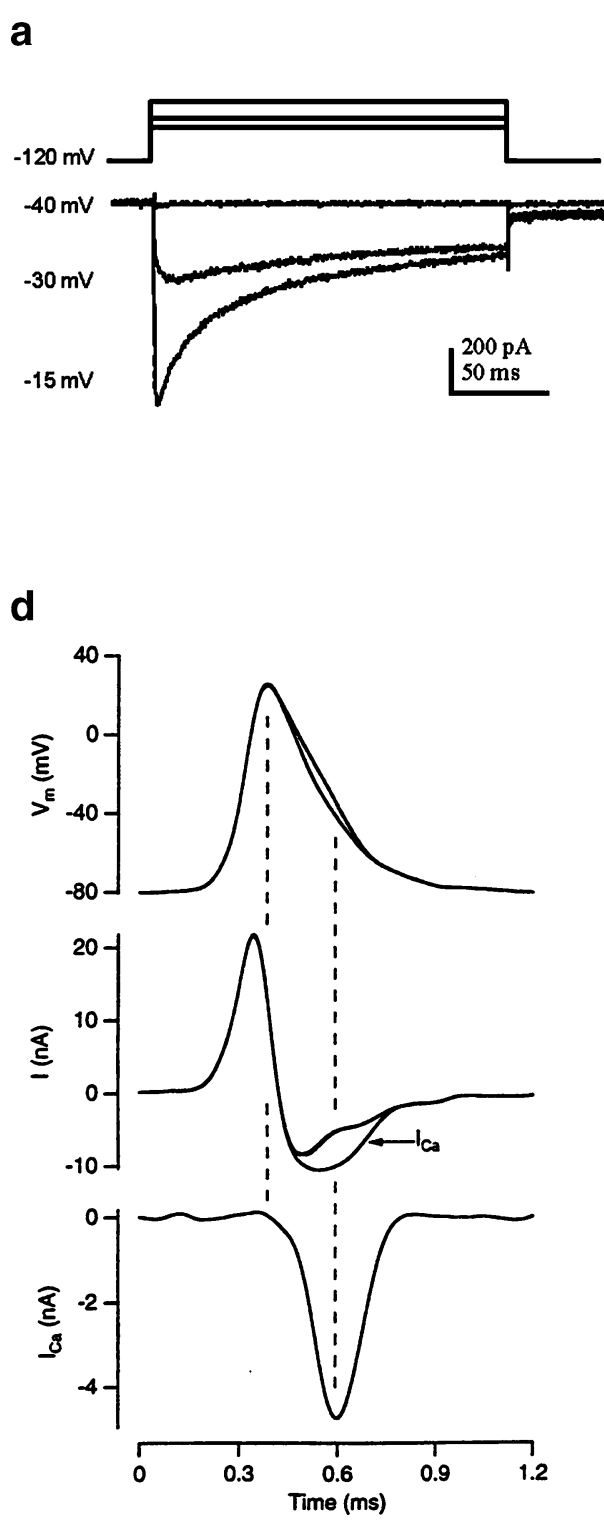

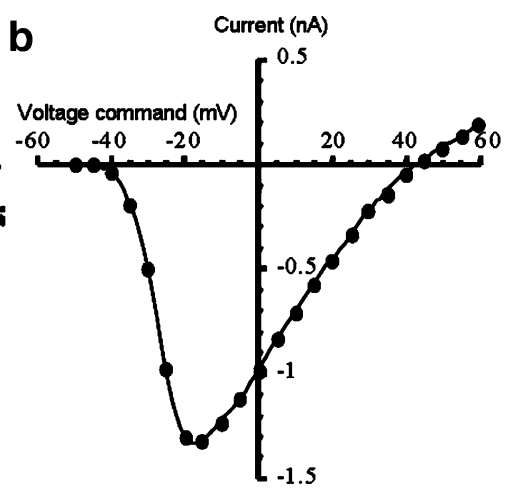

e
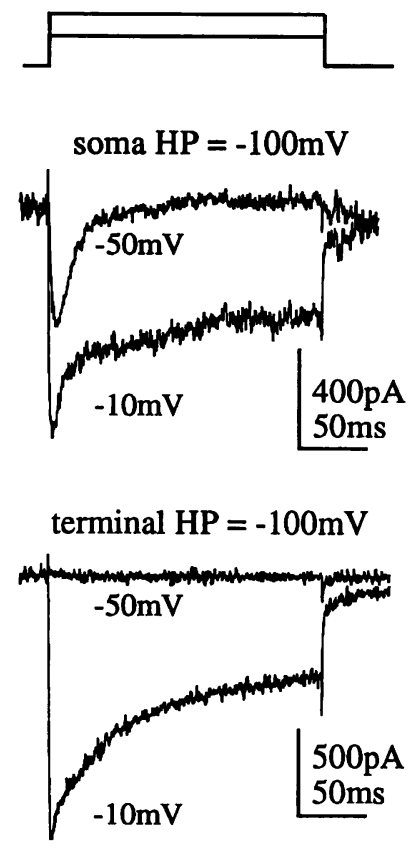

C

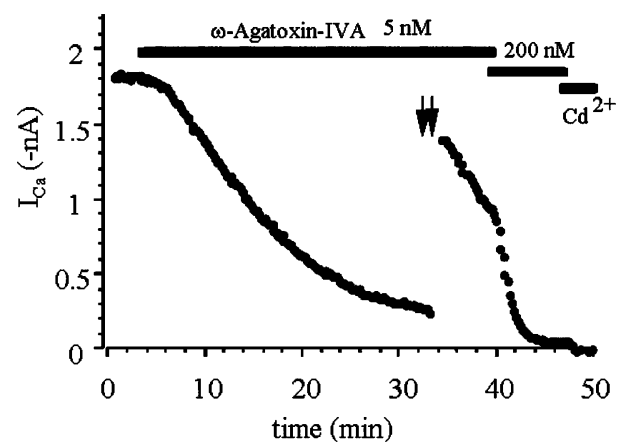

f

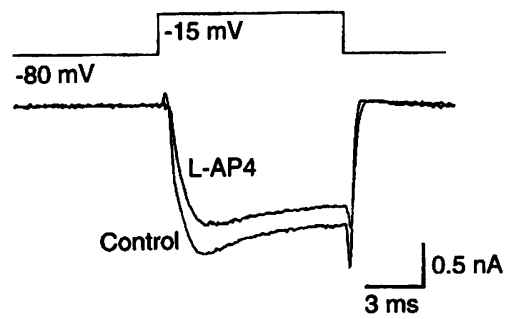

Current (nA)

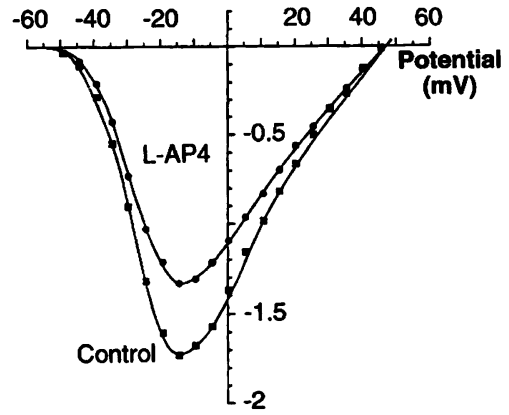

Fig. 4 Presynaptic calcium currents. a $\mathrm{Ca}^{2+}$ currents evoked from a prepulse to of $-120 \mathrm{mV}$ show no activation until step depolarisations are positive to $-40 \mathrm{mV}$. The current activates rapidly and exhibits marked inactivation at the more positive steps $(-15 \mathrm{mV})$. b The current-voltage relationship (for the same terminal as in a) shows steep voltage-dependent activation, with peak inward currents being elicited at around $-15 \mathrm{mV}$; an apparent reversal potential is observed at around $+45 \mathrm{mV}$. c In animals older than P10, most of the presynaptic $\mathrm{Ca}^{2+}$ current is blocked by $\omega$-agatoxin-IVA. Large depolarisations (double arrow) relieve the block. A high dose $(200 \mathrm{nM})$ blocks around $97 \%$ of the current and the remainder is blocked by cadmium $(50 \mu \mathrm{M})$. a-c Reprinted with permission from Elsevier, from Forsythe et al. (1998). d The $\mathrm{Ca}^{2+}$ current elicited by a presynaptic AP at $36^{\circ} \mathrm{C}$. Top Two-electrode voltage-clamp was

by frequenin/NCS-1 (neuronal $\mathrm{Ca}^{2+}$ sensor 1; Tsujimoto et al. 2002). CaV2.1 knock-out mice, which lack functional P-type channels, maintain transmission at the calyx of Held through compensation by N-type channels (Inchauspe et al. 2004; Ishikawa et al. 2005). Differences made on a single calyx of Held nerve terminal by using a measured $\mathrm{AP}$ as a voltage-clamp command waveform. Middle Total current. Bottom $\mathrm{Ca}^{2+}$ current as the difference current. Taken, with permission, from Borst and Sakmann (1998b). e $\mathrm{Ca}^{2+}$ currents of bushy cell body and calyx of Held terminal with identical voltage protocols, stepping from $-100 \mathrm{mV}$ to either $-50 \mathrm{mV}$ or $-10 \mathrm{mV}$. Note that the transient $\mathrm{Ca}^{2+}$ current is only apparent in the bushy cell body and no current is evoked at $-50 \mathrm{mV}$ in the calyx ( $H P$ holding potential). Modified, with permission, from Doughty et al. (1998). f The metabotropic glutamate receptor agonist L-AP4 reduces the amplitude of the presynaptic $\mathrm{Ca}^{2+}$ current. Single traces are superimposed and the complete $\mathrm{I} / \mathrm{V}$ is shown below. Reprinted, with permission, from Takahashi et al. (1996), copyright 1996 AAAS

between transmission in the knock-out and wildtype animal have given important clues to the physiological function of P-type channels. Although peak $\mathrm{Ca}^{2+}$ current is lower in the CaV2.1 knock-out, the major difference is the absence of $\mathrm{Ca}^{2+}$-dependent facilitation of the N-type 
presynaptic current, suggesting that this facilitation is dependent on the expression of P-type $\mathrm{Ca}^{2+}$ channels (Inchauspe et al. 2004; Ishikawa et al. 2005).

\section{Postsynaptic glutamate receptors and their developmental regulation}

The calyx of Held is a glutamatergic synapse, and early postsynaptic voltage-clamp recordings have shown a fast component of the EPSC that is sensitive to the AMPA/ kainate-receptor antagonist CNQX, and a slow component blocked by the NMDA-receptor antagonist AP-5 (Forsythe and Barnes-Davies 1993). The fast EPSC component is also blocked by GYKI 52466 showing that it is mediated exclusively by AMPA receptors (Futai et al. 2001). In young animals (P8-P10), NMDA-receptor-mediated synaptic conductance is comparable to, or larger, than the AMPA component (von Gersdorff et al. 1997; Joshi and Wang 2002) but, with postnatal maturation, the NMDAreceptor-mediated EPSC is downregulated (Taschenberger and von Gersdorff 2000; Futai et al. 2001; Joshi and Wang 2002), with only a small NMDA EPSC remaining after P20. At the same time, the decay time constant of AMPAreceptor-mediated EPSCs and miniature EPSCs (mEPSCs) is speeded up during development (Taschenberger and von Gersdorff 2000; Joshi and Wang 2002; Joshi et al. 2004), reaching values of $\sim 0.3 \mathrm{~ms}$ after P20 in rats and mice (Futai et al. 2001; Yamashita et al. 2003; Fernández-Chacón et al. 2004). The fast AMPA EPSC decay is caused by the fast rates of AMPA-receptor deactivation and desensitisation, which are probably determined by the high expression levels of the AMPA-receptor "flop" splice variants in these neurons, as revealed by single-cell polymerase chain reaction (Geiger et al. 1995; Koike-Tani et al. 2005). The fast decay of AMPA EPSCs is also observed in glutamatergic synapses made by auditory fibres in the chick nucleus magnocellularis (Zhang and Trussell 1994) and on bushy and stellate cells in the mammalian cochlear nucleus (Isaacson and Walmsley 1995; Gardner et al. 1999). Fast AMPA-receptor signalling is seen as an adaptation for the preservation of timing information in these auditory circuits (Trussell 1999).

\section{Quantal properties of transmission (N, $, q, q)$}

Since the discovery by Katz and colleagues that, at the neuromuscular junction, chemical synaptic transmission is quantal (Katz 1969), a major goal has been to understand the regulation of quantal parameters underlying transmission at a given synapse. The quantal hypothesis states that the amplitude of a postsynaptic current (PSC; or postsyn- aptic potential) is determined by the product of the quantal amplitude $q$, the number of release sites $N$ and the probability $p$ that release occurs at each site:

$P S C=q * N * p$

The quantal amplitude $q$ is a measure of membrane current induced by neurotransmitter release from a single presynaptic vesicle. The presynaptic factors $N$ and $p$ are dimensionless. The mathematical derivation of this binomial theory for quantal release (Quastel 1997; Scheuss and Neher 2001) postulates $N$ independent release sites, from each of which exactly one or no release event may occur per AP. The "release site" in this definition is equal to the physical docking site of an individual vesicle. It is important to note, however, that a "release site" in the binomial model is not identical to an active zone. A morphologically defined active zone usually has more than one docked vesicles (range: 3-8; see above), most of which are thought to be fusion-competent (Schikorski and Stevens 2001). Thus, a given stimulus could release zero, one, or several vesicles at an individual active zone: hence, "multivesicular release" (Wadiche and Jahr 2001). During multivesicular release, postsynaptic receptors become increasingly saturated, so that the postsynaptic conductance change will not grow linearly with the second, third, ... nth vesicle released simultaneously at the same active zone (Auger et al. 1998; Meyer et al. 2001). Thus, several released vesicles from a given active zone interact postsynaptically because of the limited number of postsynaptic receptors (Matveev and Wang 2000). Work on the calyx of Held has shown that $N$, depending on the means taken to minimise postsynaptic receptor saturation and on the type of stimulus used to evoke release (AP-stimulation versus direct presynaptic depolarisation or $\mathrm{Ca}^{2+}$ uncaging), often lies between two biologically relevant numbers: the number of active zones $\left(N_{\mathrm{az}}\right)$ and the number of readily releasable vesicles $\left(N_{\text {ves }}\right)$.

The quantal size $q$ at the calyx of Held has been determined from spontaneous EPSCs (either in the absence or presence of TTX) and amplitude histograms generally show means between 30-35 pA at room temperature and at a holding potential of approximately $-70 \mathrm{mV}$, with coefficients of variation of $0.3-0.5$ (see Fig. 5a; Sahara and Takahashi 2001; see also Chuhma and Ohmori 1998; Schneggenburger et al. 1999; Meyer et al. 2001; Taschenberger et al. 2005). Spontaneous EPSCs might be multiquantal if presynaptic APs trigger release; however, the application of $1 \mu \mathrm{M}$ TTX does not influence the frequency or amplitude of spontaneous EPSCs at the calyx of Held (Ishikawa et al. 2002) and, hence, spontaneous EPSC recorded in the absence of TTX are probably also true mEPSCs. In rats older than P8-P10, mEPSCs are $\sim 50 \mathrm{pA}$ (Taschenberger et al. 2005) and an increase in temperature to $\sim 37^{\circ} \mathrm{C}$ leads to an 
increase of the quantal amplitude by $\sim 50 \%$ (Kushmerick et al. 2006; M. Postlethwaite, M. Hennig, B.P. Graham and I.D. Forsythe, submitted for publication). Release from non-calyceal terminals may make a small contribution to the mEPSCs recorded in the MNTB principal cells. However, sub-threshold depolarisations of the calyx (Sahara and Takahashi 2001) or dialysis with strongly $\mathrm{Ca}^{2+}$-buffered solutions to increase presynaptic $\left[\mathrm{Ca}^{2+}\right]_{\mathrm{i}}$ beyond baseline (Sun et al. 2002; Lou et al. 2005) increases mEPSC frequency in simultaneous pre- and postsynaptic recordings, indicating that the mEPSCs occurring at rest are to a large part generated by the calyx.

The calyceal EPSC evoked by a single afferent fibre stimulation is in the range of 4-8 nA, although currents in excess of $15 \mathrm{nA}$ are not uncommon. The values are more than two orders of magnitude larger than the amplitude of a single mEPSC. To a first approximation, then, the quantal content $m(m=N * p)$ of an evoked EPSC is large (150250; Borst and Sakmann 1996; Schneggenburger et al. 1999). However, in the event of pooling of transmitter between neighbouring active zones, as might occur by spillover of glutamate (DiGregorio et al. 2002), quanta may add up non-linearly and the quantal content might be different. To investigate quantal size during evoked transmission, methods of non-stationary EPSC variance analysis (Scheuss and Neher 2001) have been applied at the calyx of Held. Meyer et al. (2001) have used a method in which the decrease of EPSC amplitudes during short-term depression
Fig. 5 Quantal parameters of synaptic transmission at the calyx of Held. a Amplitude distribution of spontaneous "miniature" EPSCs (mEPSCs). Sample traces are shown right. Taken, with permission, from Sahara and Takahashi (2001). b Variance-mean analysis of evoked EPSCs under conditions of high release probability $\left(15 \mathrm{mM}\left[\mathrm{Ca}^{2+}\right]_{\mathrm{o}}\right)$. The variancemean plot shows a maximum (right). A parabola was fitted to the four right-most lying data points (right). Extrapolation to maximal EPSC amplitudes gave an estimate of the binomial parameter $N$. Taken, with permission, from Meyer et al. (2001); copyright 2001 by the Society for Neuroscience. c Probing the size of a pool of readily releasable vesicles by strong presynaptic depolarisations. A presynaptic depolarisation to $0 \mathrm{mV}$ for $50 \mathrm{~ms}$, preceded by a brief pre-pulse to $+80 \mathrm{mV}$, evoked a presynaptic $\mathrm{Ca}^{2+}$ current $\left(\mathrm{I}_{\mathrm{Ca}}\right)$ and a large postsynaptic EPSC ( 16 nA). Deconvolution of the EPSC with the waveform of the underlying "quantal" mEPSC gave the cumulative release rate (bottom), which was fitted with a double-exponential function (bottom, dotted line). Reprinted, with permission from Elsevier, from Sakaba and Neher (2001b)
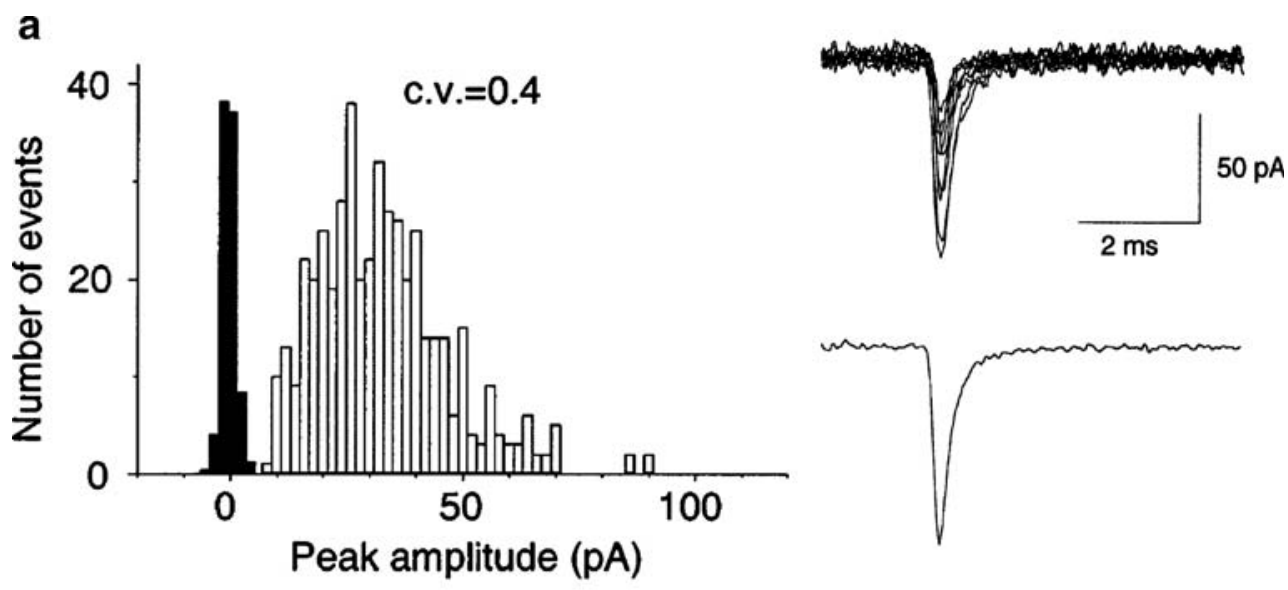

b
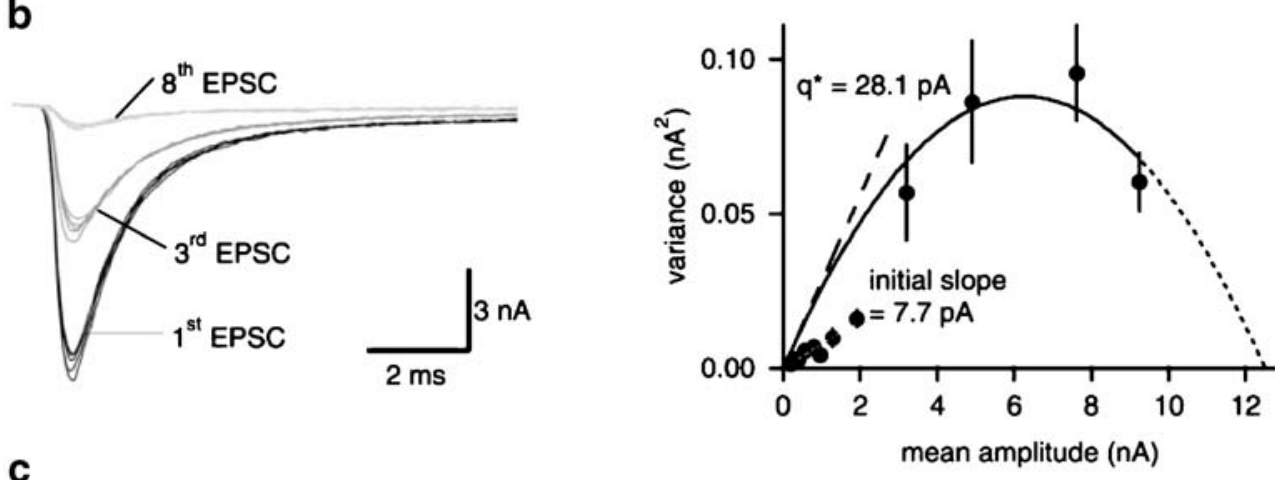

C

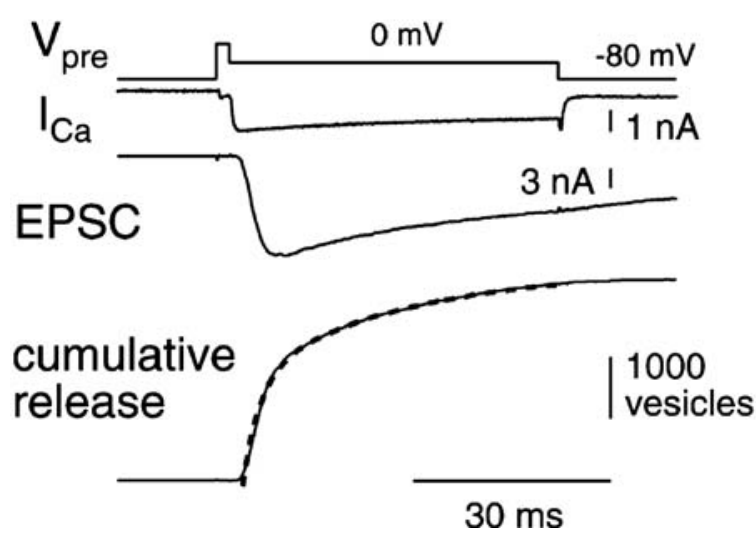


is used to lead the synapse repetitively through various states of release probability (Fig. 5b). Under normal recording conditions with $2 \mathrm{mM}\left[\mathrm{Ca}^{2+}\right]_{\mathrm{e}}$, the variance-mean relationship of peak EPSC amplitudes during depression induced by a $10-\mathrm{Hz}$ train is linear, indicating that the release probability is quite low at $2 \mathrm{mM}\left[\mathrm{Ca}^{2+}\right]_{\mathrm{e}}$. With the limiting condition of low $p$, the variance-mean data should only cover the linearly rising phase of a parabola, and the slope should be equal to the underlying quantal size. The slopes averaged $\sim 25-30 \mathrm{pA}$, which is only slightly smaller than the mean of amplitude distributions of spontaneous mEPSCs, which is $\sim 31 \mathrm{pA}$ (Meyer et al. 2001). With a similar EPSC variance-mean approach, Taschenberger et al. (2005) have determined the quantal size during evoked transmission to be somewhat higher at $\sim 50 \mathrm{pA}$. There is, therefore, no reason to assume that sub-linear quantal summation occurs during evoked EPSCs under conditions of normal release probability $\left(2 \mathrm{mM}\left[\mathrm{Ca}^{2+}\right]_{\mathrm{e}}\right)$. Thus, we can conclude that a single AP evoking an EPSC of 4-8 nA is caused by the release of between 150-250 quanta from the presynaptic terminal.

This still leaves open the question regarding the number of independent units $N$ mediating release at the calyx of Held. The binomial parameter $N$ can be estimated from EPSC variance-mean plots by extrapolating to the maximal EPSC amplitude (Silver 2003). Since the EPSC variancemean relationship is linear at normal release probability (see above), Meyer et al. (2001) enhanced the release probability by increasing $\left[\mathrm{Ca}^{2+}\right]_{\mathrm{e}}$ from $2 \mathrm{mM}$ to $15 \mathrm{mM}$; this leads to a five-fold to seven-fold potentiation of the EPSC amplitude. At $15 \mathrm{mM}\left[\mathrm{Ca}^{2+}\right]_{\mathrm{e}}$, a maximum in the EPSC variance-mean plot has been observed in many cases (Meyer et al. 2001) and the parabolic fit has been extrapolated to the maximal EPSC amplitude (Fig. 5b, right panel). Dividing this value by the quantal size should give an estimate of $N$, which was found to be $\sim 600$ on average between individual cells. Considering indications of multivesicular release and AMPA-receptor saturation (see above), Meyer et al. (2001) interpreted this value of $N$ as an upper-limit of the number of functional active zones that contribute to transmission at the calyx of Held, rather than representing a true "single vesicle release constraint" at each active zone, as postulated at other synapses based on EPSC variance-mean analysis (Korn et al. 1981; Silver et al. 2003). Although the cell-to-cell variability of the estimated parameter $N$ is large ( 200 to more than 1000; Meyer et al. 2001), there is remarkable agreement with the number of active zones estimated in the EM studies ( 500; Sätzler et al. 2002; Taschenberger et al. 2002; see above).

How many readily releasable vesicles are available at the calyx of Held? An early attempt to estimate the readily releasable pool employed a method based on cumulative EPSC amplitudes during $100 \mathrm{~Hz}$ stimulation (Schneggenburger et al. 1999). High-frequency stimulation leads to strong depression of EPSC amplitudes at the calyx of Held (Borst et al. 1995; Wang and Kaczmarek 1998; Schneggenburger et al. 1999; see also below). If depression is primarily caused by a presynaptic mechanism related to the depletion of a readily releasable pool, then backextrapolation of the cumulative EPSC amplitude to the onset time of the stimulus train should give an estimate of the readily releasable pool. This method gave values of $\sim 600$ vesicles (Schneggenburger et al. 1999) or $\sim 800$ vesicles (Bollmann et al. 2000). However, it later became apparent that the depression induced by $100-\mathrm{Hz}$ trains was not purely presynaptic (Scheuss et al. 2002; Wong et al. 2003; see below). Correcting for the decrease in quantal size caused by postsynaptic desensitisation suggests that $\sim 900$ vesicles are released during the first five pulses of a $100-\mathrm{Hz}$ train (Scheuss et al. 2002).

Direct stimulation of the presynaptic nerve terminal with prolonged presynaptic depolarisations has shown that the number of readily releasable vesicles at the calyx of Held is even larger. Sakaba and Neher (2001a) have made simultaneous pre- and postsynaptic voltage-clamp recordings under conditions aimed at isolating voltage-gated $\mathrm{Ca}^{2+}$ currents. Using long $(50 \mathrm{~ms})$ presynaptic depolarisations that evoke EPSCs of $10 \mathrm{nA}$ or larger (see also $\mathrm{Wu}$ and Borst 1999), they analysed the time-course of quantal release rates by EPSC deconvolution (Neher and Sakaba 2001 ) and found that $\sim 3,000$ vesicles are released in two kinetically distinct release phases, with time constants of $\sim 2 \mathrm{~ms}$ and $\sim 30 \mathrm{~ms}$, respectively (Fig. $5 \mathrm{c}$; Sakaba and Neher 2001b). The double-exponential time-course was interpreted as representing release from two classes of readily releasable vesicles, which are sometimes called FRP ("fastreleasing pool") and SRP ("slow-releasing pool"). The reason for the different release kinetics of FRP and SRP vesicles are not known at present; this may be caused either by a differential vesicle-to- $\mathrm{Ca}^{2+}$-channel localisation on the nanometer scale (Meinrenken et al. 2002) or by differences in the $\mathrm{Ca}^{2+}$ sensitivity between FRP and SRP vesicles, as observed in chromaffin cells (Voets 2000; for a review, see Sorensen 2004).

Presynaptic capacitance measurements after inducing presynaptic $\mathrm{Ca}^{2+}$ currents also suggest the release of a large number of vesicles $(\sim 3,300-5,000$; Sun and Wu 2001) with a time constant of about $3 \mathrm{~ms}$. Similarly, release evoked by $\mathrm{Ca}^{2+}$ uncaging, which raises $\left[\mathrm{Ca}^{2+}\right]_{\mathrm{i}}$ to $\sim 10-15 \mu \mathrm{M}$, has a fast- and slow-release component with a total release of $\sim 3,000$ vesicles as estimated by EPSC deconvolution (M. Wölfel, X. Lou and R. Schneggenburger, submitted) or $\sim 4,000$ vesicles when estimated by presynaptic capacitance measurements (Wölfel and Schneggenburger 2003). Thus, there is broad agreement across several studies that strong 
direct $\mathrm{Ca}^{2+}$ stimuli of the presynaptic nerve terminal stimulates the release of $\sim 3,000-4,000$ vesicles at the calyx of Held, probably in more than one kinetic release component.

The large number of readily releasable vesicles from functional studies reflects the overall "giant" structure of the calyx of Held, with several hundred presynaptic active zones in EM reconstructions ( $300-700$ active zones; Sätzler et al. 2002; Taschenberger et al. 2002). The number of readily releasable vesicles as defined in functional studies $(\sim 3,000-4,000$; see above) is somewhat larger than the EM estimates of morphologically docked vesicles, which were $\sim 1,100-2,800$, depending on the exact distance of vesicles from the membrane and on postnatal age (Sätzler et al. 2002; Taschenberger et al. 2002). Nevertheless, considering that the functional pool size is variable between cells (Wölfel and Schneggenburger 2003) and that ultrastructural analysis can only reconstruct one or a few calyces, the agreement between the functional and the morphological data is reasonable. If a single AP releases $\sim 150-200$ vesicles (see above), then the average release probability of a given readily releasable vesicle ( $\left.p_{\text {ves }}\right)$ must be low $(\sim 200 / 3,000$ or $5 \%-7 \%)$. Such a small release probability $p_{\text {ves }}$ has consequences for our understanding of the mechanisms of short-term plasticity at the calyx of Held (see below).

\section{Presynaptic $\mathrm{Ca}^{2+}$ signalling and the intracellular $\mathrm{Ca}^{2+}$ sensitivity of synaptic vesicle fusion}

The good accessibility of the calyx of Held to whole-cell recording has also been used for combined electrophysiological and $\mathrm{Ca}^{2+}$-imaging studies investigating presynaptic $\mathrm{Ca}^{2+}$ dynamics in a single nerve terminal. $\mathrm{Ca}^{2+}$ imaging has shown that the spatially averaged, free $\mathrm{Ca}^{2+}$ concentration $\left(\left[\mathrm{Ca}^{2+}\right]_{\mathrm{i}}\right)$ signal in the calyx has an amplitude of $\sim 400 \mathrm{nM}$ and decays with a time constant of 80-100 ms (Helmchen et al. 1997). The fast decay of $\left[\mathrm{Ca}^{2+}\right]_{\mathrm{i}}$, which is also apparent after brief trains of presynaptic stimuli $(\sim 40 \mathrm{~ms}$; Billups and Forsythe 2002) is caused by effective $\mathrm{Ca}^{2+}$. extrusion mechanisms, such as $\mathrm{Na}^{+}-\mathrm{Ca}^{2+}$ exchangers, $\mathrm{Ca}^{2+}$. ATPases in the plasma membrane (Kim et al. 2005) and uptake of $\mathrm{Ca}^{2+}$ into mitochondria (Billups and Forsythe 2002). In addition, slow $\mathrm{Ca}^{2+}$ binding to the $\mathrm{Ca}^{2+}$-binding protein parvalbumin, which is present in calyces of Held (Felmy and Schneggenburger 2004), further accelerates the decay of spatially averaged $\left[\mathrm{Ca}^{2+}\right]_{\mathrm{i}}$ (M. Müller, B. Schwaller and R. Schneggenburger, submitted).

Since transmitter release occurs at the membrane in close proximity to voltage-gated $\mathrm{Ca}^{2+}$ channels, the "local" intracellular $\mathrm{Ca}^{2+}$ signal relevant for vesicle fusion and transmitter release must be substantially higher than the spatially averaged $\left[\mathrm{Ca}^{2+}\right]_{\mathrm{i}}$. Indeed, theoretical work in the 1980s has shown that the fast time-course $(\sim 1 \mathrm{~ms})$ of transmitter release during an AP in the nerve terminal can only be explained by a similarly rapid rise and decay of the local $\mathrm{Ca}^{2+}$ signal (Chad and Eckert 1984; Simon and Llinás 1985; Yamada and Zucker 1992; Roberts 1994). Nevertheless, the relationship between the presynaptic intracellular $\mathrm{Ca}^{2+}$-concentration $\left(\left[\mathrm{Ca}^{2+}\right]_{\mathrm{i}}\right)$ and transmitter release was unknown for CNS synapses until recently. The application of simultaneous pre- and postsynaptic patch-clamp measurements, combined with presynaptic $\mathrm{Ca}^{2+}$ uncaging, has been used to study the intracellular $\mathrm{Ca}^{2+}$ requirements for vesicle fusion at the calyx of Held (Bollmann et al. 2000; Schneggenburger and Neher 2000; Felmy et al. 2003b; Wölfel and Schneggenburger 2003; Bollmann and Sakmann 2005; Lou et al. 2005).

Figure 6 a shows a $\mathrm{Ca}^{2+}$-uncaging experiment at the calyx of Held (Schneggenburger and Neher 2000). The good accessibility of the calyx to whole-cell patch-clamp recordings was used to load the nerve terminal with a mixture of a $\mathrm{Ca}^{2+}$ loaded light-sensitive $\mathrm{Ca}^{2+}$ chelator (DM-nitrophen) and a suitable low-affinity $\mathrm{Ca}^{2+}$ indicator (fura-2FF in the case of Fig. 6a). A brief flash of light ( $\sim 1 \mathrm{~ms}$; Schneggenburger and Neher 2000) or a UV-laser pulse (Bollmann et al. 2000) then photolyzed part of the DM-nitrophen, leading to a rapid increase in $\left[\mathrm{Ca}^{2+}\right]_{\mathrm{i}}$ that returned slowly $\left(\mathrm{t}_{1 / 2}: \sim 150 \mathrm{~ms}\right)$ to baseline (Fig. 6a, left). Such step-like $\left[\mathrm{Ca}^{2+}\right]_{\mathrm{i}}$ elevations triggered transmitter release that was measured as an EPSC in simultaneous postsynaptic whole-cell recording (Fig. 6a, right). The amount and the kinetics of release depended on the $\left[\mathrm{Ca}^{2+}\right]_{\mathrm{i}}$ reached after the flash.

During $\mathrm{Ca}^{2+}$ uncaging, spatial gradients of $\left[\mathrm{Ca}^{2+}\right]_{\mathrm{i}}$ as occur during the opening of presynaptic $\mathrm{Ca}^{2+}$ channels are avoided. Since the $\mathrm{Ca}^{2+}$-loaded DM-nitrophen is most probably homogeneously distributed in the cytosol, $\mathrm{Ca}^{2+}$ uncaging should generate homogeneous $\left[\mathrm{Ca}^{2+}\right]_{\mathrm{i}}$ elevations (Naraghi et al. 1998). Thus, the $\left[\mathrm{Ca}^{2+}\right]_{\mathrm{i}}$ measured after uncaging is equal to the $\left[\mathrm{Ca}^{2+}\right]_{\mathrm{i}}$ signal that drives transmitter release. An estimate of the local $\mathrm{Ca}^{2+}$ transient at the site of vesicle fusion can then be obtained by backcalculation from the measured $\mathrm{Ca}^{2+}$ sensitivity in a "reverse approach" (for a review, see Schneggenburger and Neher 2005). First, the relationship between transmitter release rate and presynaptic $\left[\mathrm{Ca}^{2+}\right]_{\mathrm{i}}$ is measured and fitted with a kinetic model of $\mathrm{Ca}^{2+}$ binding and vesicle fusion, taking into account the kinetic parameters of transmitter release, such as $\mathrm{Ca}^{2+}$-dependent synaptic delay. The models incorporate five $\mathrm{Ca}^{2+}$-binding steps, since the relationship between transmitter release and $\left[\mathrm{Ca}^{2+}\right]_{\mathrm{i}}$ is highly non-linear, with a slope of $4-5$ in a double-logarithmic data plot across a range of $\sim 2-8 \mu \mathrm{M}\left[\mathrm{Ca}^{2+}\right]_{\mathrm{i}}$ (see also Fig. $6 \mathrm{~b}$, right). The parameters of the model can then be used to predict the time-course and amplitude of the local $\mathrm{Ca}^{2+}$ signal as 
a
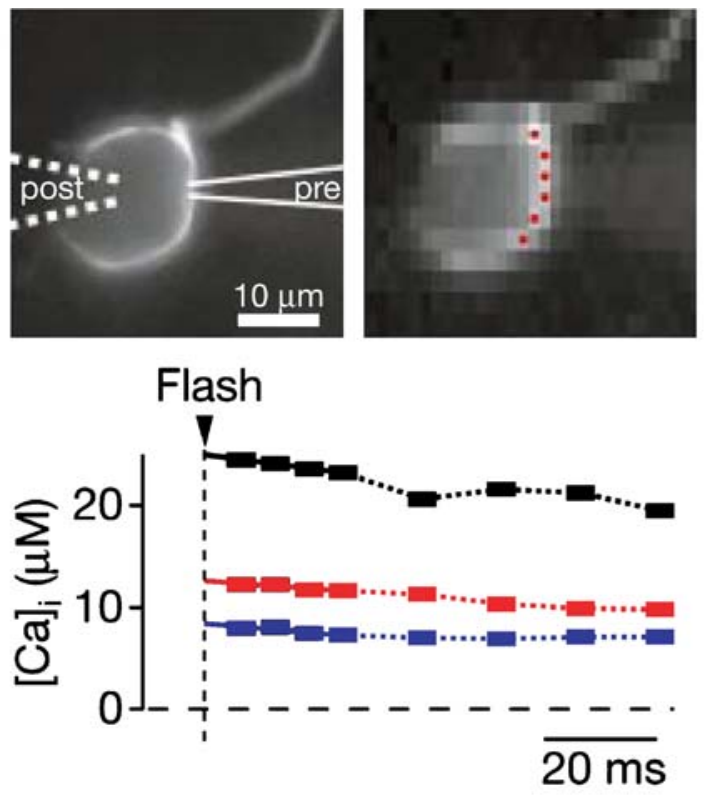

b

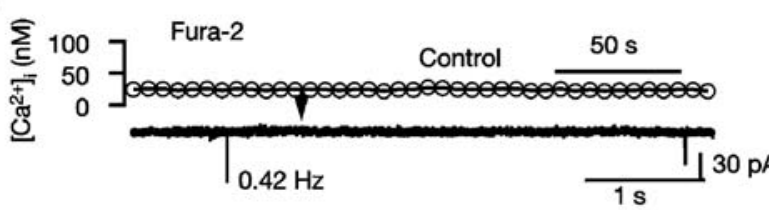

$\sum_{\exists} 0.27$ Fura-2

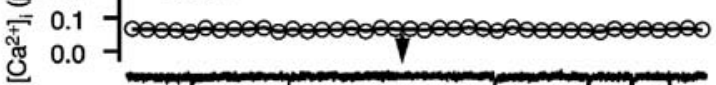

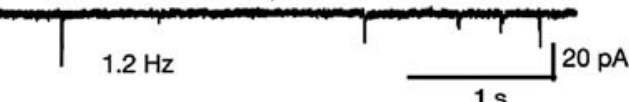

$\sum_{1} 1.07 \quad$ Fura-4F

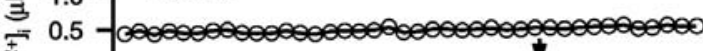

芩 0.0

C

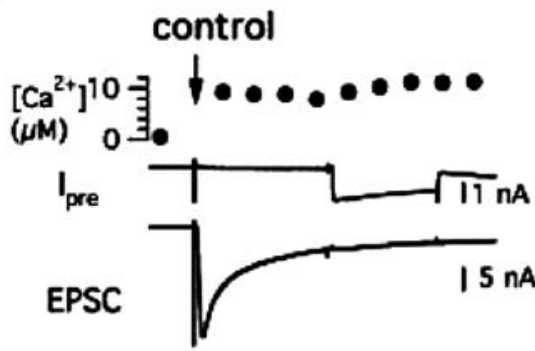

rel.

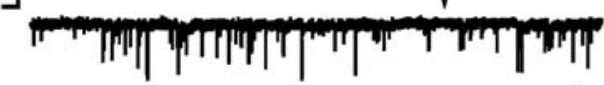

$16 \mathrm{~Hz}$

$30 \mathrm{pA}$

$1 \mathrm{~s}$
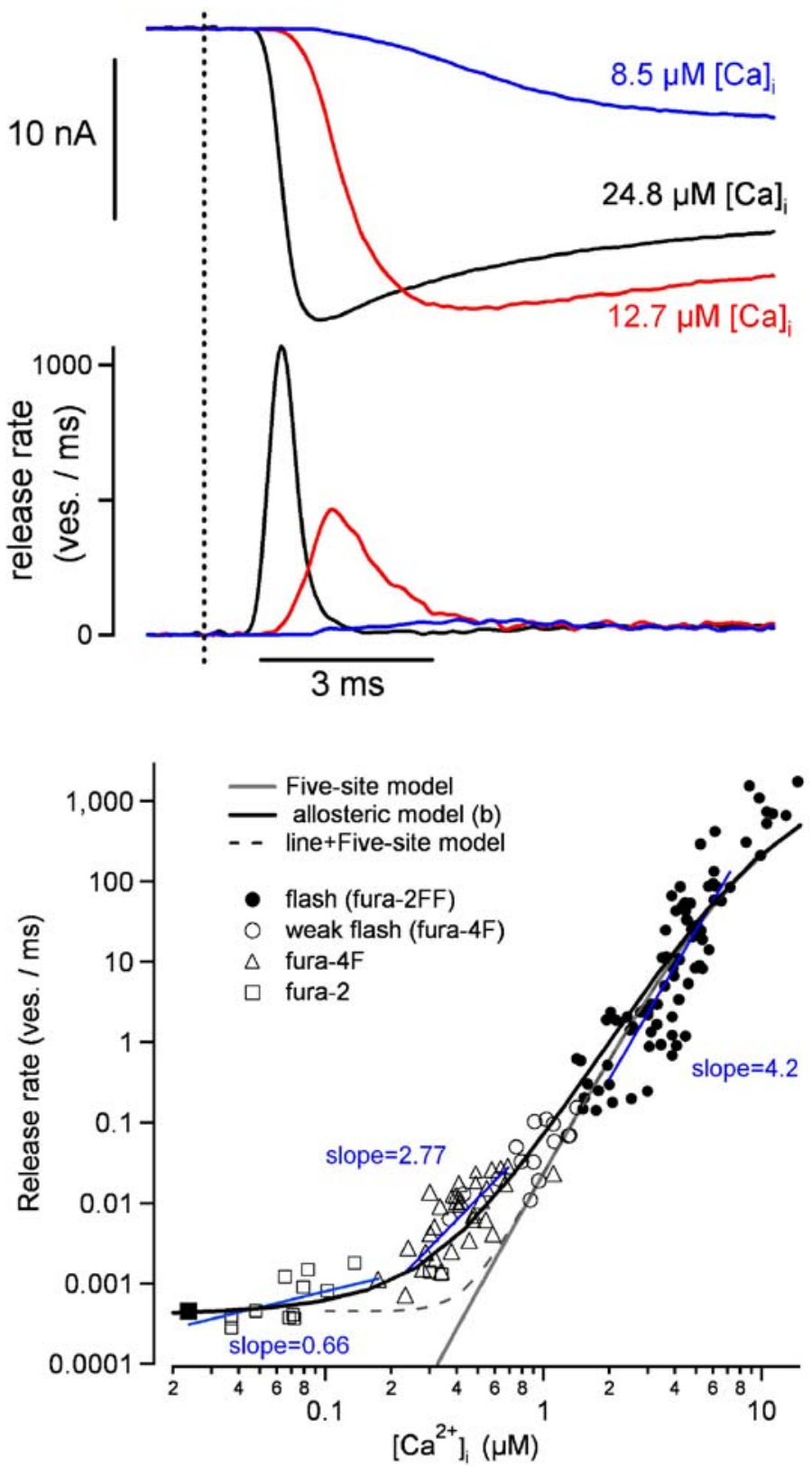

rate
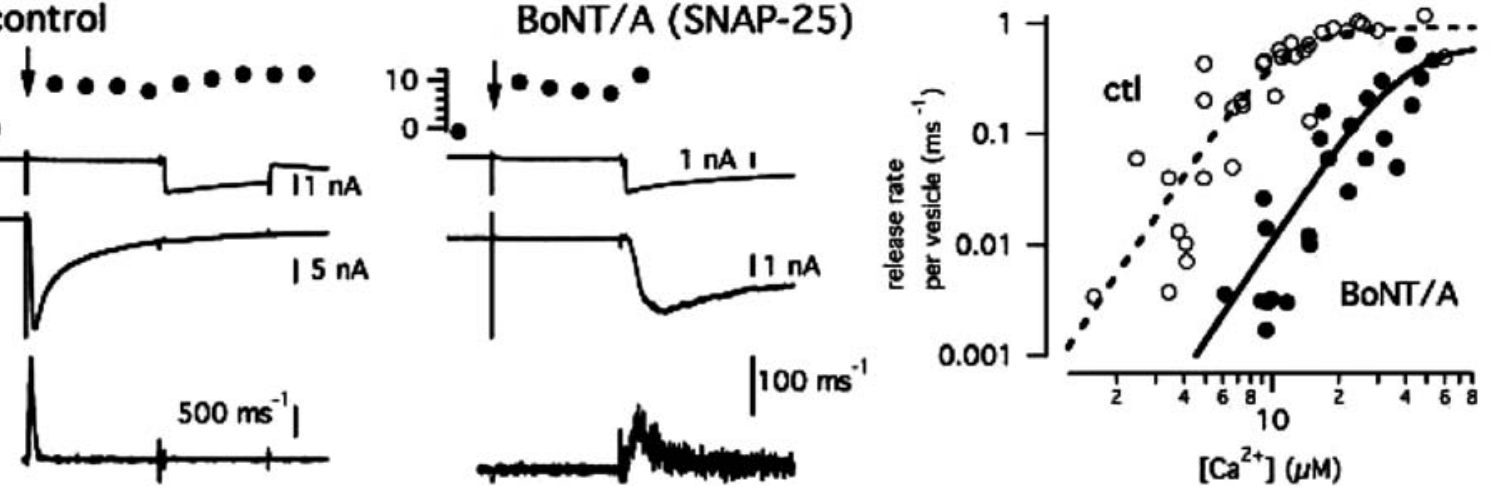
4 Fig. 6 Intracellular $\mathrm{Ca}^{2+}$ sensitivity of synaptic vesicle fusion. a Presynaptic $\mathrm{Ca}^{2+}$ uncaging at the calyx of Held. Left, top A calyx filled with fura-2FF and $\mathrm{Ca}^{2+}$-loaded DM-nitrophen imaged at low and high resolution during and after the experiment, respectively. Left, bottom Three flashes with different intensities elevated the presynaptic intracellular $\mathrm{Ca}^{2+}$ concentration $\left(\left[\mathrm{Ca}^{2+}\right]_{\mathrm{i}}\right)$ to $\sim 8,12$ and $25 \mu \mathrm{M}$. Right, top The EPSCs evoked by these $\left[\mathrm{Ca}^{2+}\right]_{\mathrm{i}}$ elevations. Right, bottom From the EPSCs, the transmitter release rates were determined by EPSC deconvolution. Adapted, with permission from MacMillan, from Schneggenburger and Neher (2000). b $\mathrm{Ca}^{2+}$ dependency of transmitter release over an extended range of presynaptic $\left[\mathrm{Ca}^{2+}\right]_{\mathrm{i}}$. Left Simultaneous pre- and postsynaptic recordings were made at resting $\left[\mathrm{Ca}^{2+}\right]_{\mathrm{i}}$ in the presynaptic terminal (top) or with strongly $\mathrm{Ca}^{2+}$ buffered solutions aimed at elevating the presynaptic $\left[\mathrm{Ca}^{2+}\right]_{i}$ above resting values (middle, bottom). Note that elevating $\left[\mathrm{Ca}^{2+}\right]_{i}$ above baseline leads to an increased transmitter release rate, as is apparent by the increased mEPSC frequency. Right The $\mathrm{Ca}^{2+}$ sensitivity of asynchronous release measured by infusing terminals with strongly $\mathrm{Ca}^{2+}$-buffered solutions (open symbols; see $\mathbf{b}$, left) is contiguous with the $\mathrm{Ca}^{2+}$ sensitivity as measured by $\mathrm{Ca}^{2+}$ uncaging (filled symbols). The data were fitted with an "allosteric" model of $\mathrm{Ca}^{2+}$ activation of vesicle fusion (black line). Adapted, with permission from MacMillan, from Lou et al. (2005). c Botulinus toxin A (BotTx A), which specifically cleaves the SNARE-protein SNAP-25, induces a rightward-shift of the intracellular $\mathrm{Ca}^{2+}$ sensitivity of vesicle fusion. Left $\mathrm{Ca}^{2+}$-uncaging stimulus (arrow), followed by a strong presynaptic depolarisation in a control cell. Middle Same protocol applied in a calyx recorded with BotTx A added to the presynaptic patch pipette. Right Relationship between release rates (normalised to the number of readily releasable vesicles) and presynaptic $\left[\mathrm{Ca}^{2+}\right]_{\mathrm{i}}$ after the flash is shifted to the right in the presence of BotTx A. Adapted, with permission, from Sakaba et al. (2005), copyright 2005 AAAS

"seen" by an average readily releasable vesicle. A brief local $\mathrm{Ca}^{2+}$ signal of 10-25 $\mathrm{MM}$ amplitude, with a half-width of $\sim 0.5 \mathrm{~ms}$ is compatible with transmitter release following a presynaptic AP (Bollmann et al. 2000; Schneggenburger and Neher 2000).

Comparison of this transient local $\mathrm{Ca}^{2+}$ signal at the release site with the spatially averaged $\left[\mathrm{Ca}^{2+}\right]_{i}$ signal of the whole terminal ( $400 \mathrm{nM}$; see above) shows that the local $\mathrm{Ca}^{2+}$ signal is about 20-40 times higher than the spatially averaged signal and that it decays $\sim 50-100$ times faster. The brief duration of the back-calculated local $\mathrm{Ca}^{2+}$ signal $(\sim 0.5 \mathrm{~ms})$ was recently confirmed more directly (Bollmann and Sakmann 2005). In this study, $\mathrm{Ca}^{2+}$ uncaging induced by laser-pulses was used to produce rapidly decaying $\left[\mathrm{Ca}^{2+}\right]_{\mathrm{i}}$ transients by including millimolar concentrations of the slow $\mathrm{Ca}^{2+}$ buffer EGTA in the presynaptic pipette solution. The fluorescence change of a low-affinity $\mathrm{Ca}^{2+}$ indicator was measured after the laser-pulses, and the $\left[\mathrm{Ca}^{2+}\right]_{\mathrm{i}}$ transient, which was slightly faster than the measured fluorescence change, was back-calculated according to kinetic modelling. EPSC amplitude and rise-time (reflecting the amount and kinetics of transmitter release) depended on the width of the presynaptic $\left[\mathrm{Ca}^{2+}\right]_{i}$ transient. Brief $\left[\mathrm{Ca}^{2+}\right]_{\mathrm{i}}$ transients with a half-width of less than $0.5 \mathrm{~ms}$ were needed to produce EPSCs with a similarly rapid rising phase as those produced during a presynaptic AP (Bollmann and Sakmann 2005).

Recently, the intracellular $\mathrm{Ca}^{2+}$ requirements for low rates of asynchronous transmitter release have been investigated at the calyx of Held (Lou et al. 2005; see Fig. 6b). The presynaptic terminal was dialysed with strongly $\mathrm{Ca}^{2+}$ buffered pipette solutions aimed at clamping the resting $\left[\mathrm{Ca}^{2+}\right]_{\mathrm{i}}$ to values between $50 \mathrm{nM}$ and $800 \mathrm{nM}$ and the effective $\left[\mathrm{Ca}^{2+}\right]_{\mathrm{i}}$ was measured with an indicator dye. This showed that increasing $\left[\mathrm{Ca}^{2+}\right]_{\mathrm{i}}$ above the resting value of $\sim 30 \mathrm{nM}$ in the calyx led to a clear increase in the frequency of spontaneous mEPSCs (Fig. 6b, left) and, thus, that "spontaneous" release was not completely independent of $\left[\mathrm{Ca}^{2+}\right]_{\mathrm{i}}$. Plotting mEPSC frequency as a function of $\left[\mathrm{Ca}^{2+}\right]_{\mathrm{i}}$ gave a slope of less than 1 in the range of low $\left[\mathrm{Ca}^{2+}\right]_{i}$ (Fig. 6b, right). Interestingly, the intracellular $\mathrm{Ca}^{2+}$ dependency of mEPSC frequency was shown to be contiguous with the $\left[\mathrm{Ca}^{2+}\right]_{i}$ dependency of release evoked by weak flashes (Fig. 6b, right, open circles) and with the peak release rates observed after flashes that elevated $\left[\mathrm{Ca}^{2+}\right]_{\mathrm{i}}$ to $>2 \mu \mathrm{M}$ (Fig. 6b, right, closed circles; Lou et al. 2005). The authors concluded that the same $\mathrm{Ca}^{2+}$-sensing mechanism mediated both asynchronous release close to resting $\left[\mathrm{Ca}^{2+}\right]_{\mathrm{i}}$ and transient release with $\mathrm{Ca}^{2+}$ uncaging steps to higher $\left[\mathrm{Ca}^{2+}\right]_{i}$. In order to explain the strongly reduced $\mathrm{Ca}^{2+}$ cooperativity at low $\left[\mathrm{Ca}^{2+}\right]_{i}$, an "allosteric" model was proposed in which vesicle fusion could occur at low rates in the absence of $\mathrm{Ca}^{2+}$ binding, although binding of an increasing number of $\mathrm{Ca}^{2+}$ ions progressively increased the vesicle fusion rate constants (Lou et al. 2005). This model is analogous to allosteric models for ligand-gated ion channel activation (e.g. for cyclicnucleotide gated channels; Li et al. 1997), where evidence for ion channel opening in the absence of ligand binding has been obtained.

The finding that the $\mathrm{Ca}^{2+}$ cooperativity in triggering vesicle fusion is low around resting $\left[\mathrm{Ca}^{2+}\right]_{\mathrm{i}}(\sim 1)$ and that it increases to a value of $\sim 4$ with $\left[\mathrm{Ca}^{2+}\right]_{i}$ stimuli of higher amplitudes (Fig. 6b, right) is also likely to be of particular functional relevance. If a high cooperativity mechanism operated close to baseline $\left[\mathrm{Ca}^{2+}\right]_{\mathrm{i}}$, then small sub-micromolar elevations of residual $\left[\mathrm{Ca}^{2+}\right]_{\mathrm{i}}$ would produce strong increases in transmitter release. This would be highly undesirable as it would generate excessive "tonic" turnover of transmitter quanta at a synapse designed to transmit information phasically, locked to each presynaptic AP. The data by Lou et al. (2005) also reveal an amazing dynamic range covered by the $\mathrm{Ca}^{2+}$ regulation of transmitter release: from a "spontaneous" release rate of $\sim 1 \mathrm{~Hz}$ at resting $\left[\mathrm{Ca}^{2+}\right]_{\mathrm{i}}$ to a peak transmitter release of $\sim 300$ vesicles $/ \mathrm{ms}$ during the AP (Schneggenburger and Neher 2000; Taschenberger et al. 2005). Thus, the presynaptic AP transiently increases the rate of transmitter release by 
$\sim 300,000$-fold over resting values or by more than five orders of magnitude for a $\left[\mathrm{Ca}^{2+}\right]_{\mathrm{i}}$ elevation of approximately two to three orders of magnitude (Fig. 6b, right). This is only possible with a highly non-linear mechanism coupling the rise of $\left[\mathrm{Ca}^{2+}\right]_{i}$ to transmitter release. Synaptotagmin-1 has been identified as the $\mathrm{Ca}^{2+}$ sensor for a fast component of transmitter release in hippocampal neurons (Geppert et al. 1994; Fernández-Chacón et al. 2001). At the calyx of Held, where synaptotagmin-1 is not expressed, the close homologue synaptotagmin-2 might play this role (Pang et al. 2006). However, the molecular mechanism responsible for the high cooperativity of $\mathrm{Ca}^{2+}$ in vesicle fusion is still unknown and needs to be addressed in future work.

A recent study has analysed the molecular determinants of $\mathrm{Ca}^{2+}$-induced vesicle fusion by perfusing calyces with various botulinum and tetatanus neurotoxins (Sakaba et al. 2005). These toxins proteolytically cleave SNAREs at specific sites and thereby inhibit transmitter release (for a review, see Humeau et al. 2000). When Sakaba et al. (2005) included BotTx $\mathrm{C} 1$ or tetanus toxin (TeT), which specifically cleaves syntaxin or synaptobrevin, respectively, in the presynaptic recording pipette, release was reduced but the remaining release has similar kinetics (an "all-or-none" effect of the toxins). On the other hand, in the presence of BotTx A, which cleaves off the last nine amino acids of SNAP-25, release in response to a $\mathrm{Ca}^{2+}$-uncaging step to about $10 \mu \mathrm{M}\left[\mathrm{Ca}^{2+}\right]_{\mathrm{i}}$ was nearly abolished, although higher levels of $\mathrm{Ca}^{2+}$ uncaging could almost fully rescue release in the presence of BotTx A (Fig. 6c, middle; Sakaba et al. 2005). Analysis of the release rate versus $\left[\mathrm{Ca}^{2+}\right]_{\mathrm{i}}$ relationship over a range of $\sim 3-60 \mu \mathrm{M}\left[\mathrm{Ca}^{2+}\right]_{\mathrm{i}}$ showed that BotTx A induced an approximately four-fold rightward shift of the intracellular $\mathrm{Ca}^{2+}$ sensitivity of vesicle fusion, without a change in the apparent $\mathrm{Ca}^{2+}$ cooperativity as revealed by the similar slopes in the double-logarithmic plots (Fig. 6c, right). Thus, interfering with the integrity of the presynaptic SNARE-complex can lead to a decrease in the $\mathrm{Ca}^{2+}$ sensitivity of release.

\section{Mechanisms of short-term plasticity}

Repetitive stimulation of afferent fibres leads to a pronounced frequency-dependent depression of EPSCs at the calyx of Held synapse (Borst et al. 1995; von Gersdorff et al. 1997; Wang and Kaczmarek 1998). Thus, the calyx is a depressing synapse but facilitation of the second EPSC amplitude is sometimes observed in response to highfrequency trains (e.g. Schneggenburger et al. 1999). The facilitation can be uncovered by lowering the initial release probability with low extracellular $\left[\mathrm{Ca}^{2+}\right]$ (Barnes-Davies and Forsythe 1995; Borst et al. 1995) or by lowering the quantal output during the first stimulation in paired pre- and postsynaptic whole-cell recording (Sakaba and Neher 2001a; Felmy et al. 2003b) and under conditions where postsynaptic desensitisation has been minimised (Wong et al. 2003). Felmy et al. (2003a,b) have studied the mechanism of short-term facilitation and found, by using $\mathrm{Ca}^{2+}$ uncaging, that the intracellular $\mathrm{Ca}^{2+}$ sensitivity of vesicle fusion is unchanged during facilitation. Following prolonged high-frequency stimulation, the calyx of Held shows a pronounced post-tetanic potentiation of transmitter release, which is mediated by a mechanism dependent on residual $\mathrm{Ca}^{2+}$, but different from that implicated in short-term facilitation (Habets and Borst 2005; Korogod et al. 2005). Thus, short-term plasticity at the calyx of Held appears to be similar to that at the neuromuscular junction, with depression prevailing during high-frequency trains at normal release probability and a transient overshoot of transmission following such trains (Liley and North 1953; Elmquist and Quastel 1965). Longer-lasting forms of plasticity have so far not been apparent at the calyx of Held.

Direct whole-cell recordings from the nerve terminal allow assessment of whether changes in the AP waveform or changes in AP-mediated $\mathrm{Ca}^{2+}$ influx contribute to synaptic depression. During the strong depression induced by $100-\mathrm{Hz}$ trains, AP amplitude decreases slightly and becomes broader; however, presynaptic voltage-clamp experiments show similar $\mathrm{Ca}^{2+}$-current integrals activated by early and late AP waveforms (Borst and Sakmann 1999), suggesting that changes in AP waveform may not contribute to the depression of release during brief highfrequency trains. At lower frequencies $(2-30 \mathrm{~Hz})$, the $\mathrm{Ca}^{2+}$ current decreased with repetitive stimulation because of $\mathrm{Ca}^{2+}$-current inactivation ( $\mathrm{Xu}$ and $\mathrm{Wu} 2005$ ). Although the relative reduction of $\mathrm{Ca}^{2+}$ current is small (Fig. 7a, right), with the high-power relationship between $\mathrm{Ca}^{2+}$ current and release (3.6 as measured by $\mathrm{Xu}$ and $\mathrm{Wu} 2005$ ), even a small decrease is expected to be highly efficient in modulating transmitter release and the decrease expected by a simple $3.6^{\text {th }}$ power relationship predicted the observed depression of EPSC amplitudes (Fig. 7a, right; Xu and Wu 2005). Thus, $\mathrm{Ca}^{2+}$-current inactivation, which was first shown to mediate the "deep" depression observed after prolonged high-frequency stimulation at the calyx of Held (Forsythe et al. 1998), also contributes to the depression observed during the onset of low-to-intermediate frequency trains $(2-30 \mathrm{~Hz})$.

Depletion of a readily releasable vesicle pool was also postulated to contribute to depression at the calyx of Held (von Gersdorff et al. 1997; Schneggenburger et al. 1999; Weis et al. 1999). In the following years it became clear, however, that the AMPA-R desensitisation that had been observed earlier at glutamatergic chick endbulb synapses (Trussell et al. 1993; Otis et al. 1996) might play a larger role in depression at the calyx of Held than initially 
suspected. Neher and Sakaba (2001) have found that cyclothiazide, which very effectively slows the rate of desensitisation of AMPA-R in MNTB principal cells (Koike-Tani et al. 2005), reduces the depression of EPSCs observed in simultaneous pre- and postsynaptic recordings. Using EPSC fluctuation analysis of the peak EPSC amplitudes during $100-\mathrm{Hz}$ trains at elevated release probability, Scheuss et al. (2002) estimated that, during the third to fifth EPSC in a $100-\mathrm{Hz}$ train, the quantal amplitude $q$ was reduced to $\sim 35 \%$ of its initial value (see Fig. 7 c). The reduction of $q$ was less strong in the presence of CTZ; with CTZ and kynurenic acid (a low-affinity AMPA-R antagonist), $q$ was stable throughout the first five pulses of a 100$\mathrm{Hz}$ train. Thus, the reduction of $q$ during the second to the fifth stimulus of a $100-\mathrm{Hz}$ train is probably caused by desensitisation of postsynaptic AMPA-Rs. Taschenberger et al. (2002) and Wong et al. (2003) have also shown, by using the low-affinity fast-off-rate antagonist, kynurenic acid (and CTZ in some cases), that postsynaptic mechanisms contribute to depression (Fig. 7b). The postsynaptic contribution to depression is reduced with developmental maturation (Taschenberger et al. 2002, 2005), perhaps because changes in calyx morphology allow faster diffusion of glutamate from the synaptic cleft (Renden et al. 2005).

The extent to which vesicle pool depletion contributes to depression remains unclear. Several different mechanisms of depression are present at the calyx of Held (see above) and with a large pool of readily releasable vesicles (see above; Schneggenburger and Neher 2000; Sakaba and Neher 2001a; Sun and Wu 2001; Wölfel and Schneggenburger 2003), the role of vesicle pool depletion early during high-frequency trains seems less significant. However, a key finding is that
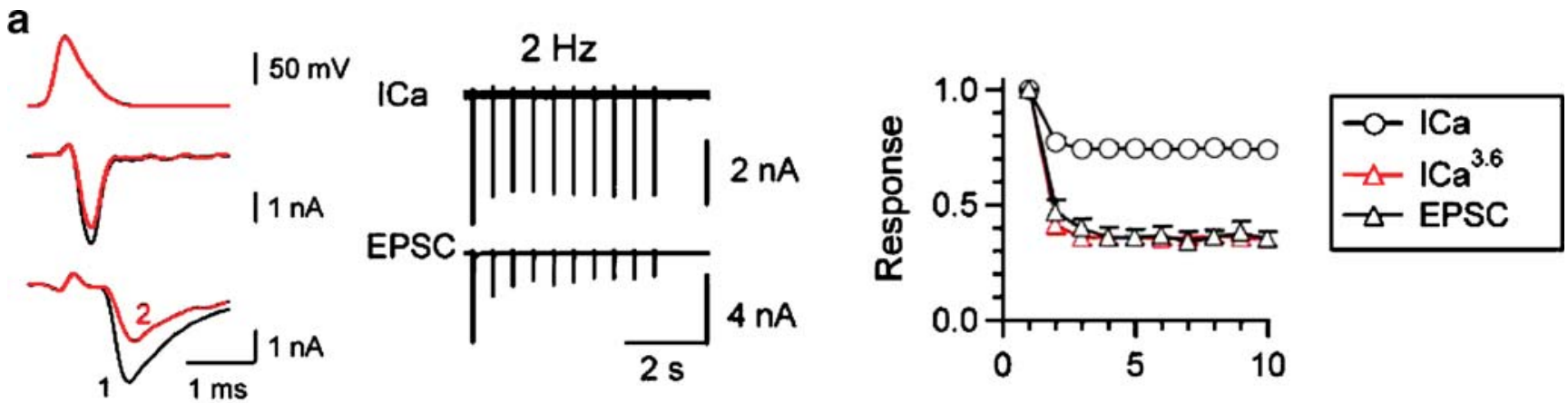

b
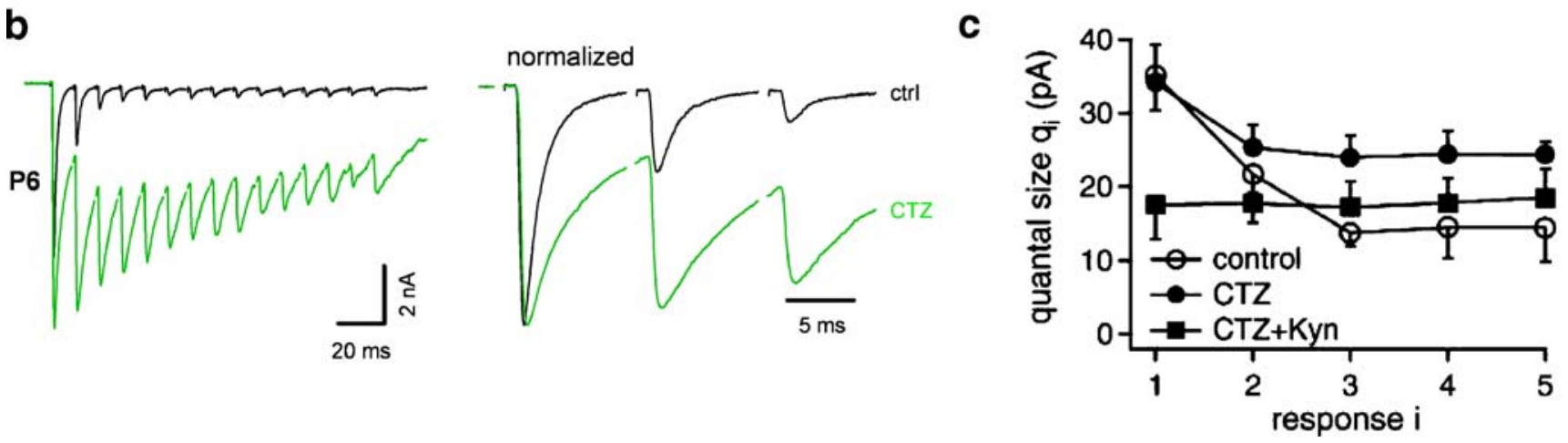

Fig. 7 Mechanisms of short-term depression at the calyx of Held. a Inactivation of presynaptic $\mathrm{Ca}^{2+}$ current contributes to synaptic depression. Left A presynaptic AP (top) was used as a voltage-clamp command waveform and was applied twice with an interval of $500 \mathrm{~ms}$. The second pulse (red traces) evoked a smaller $\mathrm{Ca}^{2+}$ current (middle) and a smaller EPSC (bottom). Middle $\mathrm{I}_{\mathrm{Ca}}$ (top) and EPSCs (bottom) evoked by 10 short presynaptic depolarisations at $2 \mathrm{~Hz}$. Note the decrease in $\mathrm{I}_{\mathrm{Ca}}$ and EPSCs from the second depolarisation onwards. Right The relative $\mathrm{I}_{\mathrm{Ca}}$ and EPSC amplitudes plotted as a function of stimulus number (black symbols). Because of the high-power relationship between $\mathrm{Ca}^{2+}$ current and EPSCs with an exponent of 3.6, the reduction in $\mathrm{I}_{\mathrm{Ca}}$ might fully explain the depression of EPSCs. Modified, with permission from Elsevier, from $\mathrm{Xu}$ and $\mathrm{Wu}$ (2005). b Postsynaptic AMPA-receptor (AMPA-R) desensitisation contributes to depression during high-frequency trains. Left EPSCs in response to a $100-\mathrm{Hz}$ train of afferent fibre stimuli, recorded at P6 (black trace control, green trace after application of $50 \mu \mathrm{M}$ cyclothiazide to remove AMPA-R desensitisation, CTZ cyclothiazide). CTZ reduced the depression of the 2nd and 3rd EPSCs. Modified, with permission from Elsevier, from Taschenberger et al. (2002). c Estimated average quantal sizes during the EPSCs evoked by a short $100-\mathrm{Hz}$ train of stimuli, analysed from EPSC variance and covariance under three different pharmacological recording conditions. Note that, under control conditions, the quantal size of $\sim 35 \mathrm{pA}$ during the first EPSC was strongly reduced with subsequent stimuli. In the presence of CTZ $(100 \mu \mathrm{M})$, or CTZ and kynurenic acid $(C T Z+K y n ; 1 \mathrm{mM})$, the quantal size reduction was less or absent, respectively, indicating that postsynaptic AMPA-R desensitisation and/or saturation was the cause for the observed quantal size reduction. Taken from Scheuss et al. (2002), copyright 2002 by the Society for Neuroscience 
certain stimuli used for measuring pool sizes (such as prolonged voltage-clamp depolarisations, see Fig. 5c; Sakaba and Neher 2001a) or $\mathrm{Ca}^{2+}$-uncaging stimuli (M. Wölfel, X. Lou and R. Schneggenburger, submitted) lead to two components of release that correspond to rapidly and to more reluctantly releasable vesicles (see also Moulder and Mennerick 2005). Sakaba (2006) has shown that the "phasic" release that is time-locked to brief presynaptic depolarisations is mediated, as expected, by fast-releasing vesicles and that reluctant vesicles only contribute to the asynchronous release that builds up during the train of depolarisations. On the other hand, increasing the release probability during trains of APs leads to successively larger cumulative peak EPSC amplitudes in hippocampal synapses (Moulder and Mennerick 2005). Moreover, strong $\mathrm{Ca}^{2+}$ uncaging stimuli beyond $15 \mu \mathrm{M}\left[\mathrm{Ca}^{2+}\right]_{\mathrm{i}}$ release an increasing number of vesicles in the fast component at the calyx of Held (M. Wölfel, X. Lou and R. Schneggenburger, submitted). Both findings suggest that reluctant vesicles can also be released rapidly, provided that $\left[\mathrm{Ca}^{2+}\right]_{\mathrm{i}}$ is sufficiently high. Clearly, more work is needed to define the relationship between the fast-releasing and the more reluctantly released vesicles and to determine the reasons for their different release kinetics.

\section{Endocytosis and presynaptic vesicle recycling}

After fusion, vesicles are recycled for use, and the early steps of this recycling pathway are mediated by endocytic uptake of the vesicle membrane (Südhof 2004). A long-standing controversy exists with regard to the contribution of "kiss-and run" release mechanisms (which would imply extremely rapid endocytosis) and slower mechanisms of membrane re-uptake (Royle and Lagnado 2003). At the calyx of Held, presynaptic membrane capacitance $\left(\mathrm{C}_{\mathrm{m}}\right)$ measurements can be used to detect the amount of exocytosis (Sun and Wu 2001; Taschenberger et al. 2002; Wölfel and Schneggenburger 2003). The decrease in $C_{m}$ following the stimulus probably indicates membrane re-uptake by endocytosis, as has been established in other model systems (for a review, see Royle and Lagnado 2003). Exocytosis evoked by a short AP-equivalent voltage-step at the calyx of Held induced a measurable capacitance increase followed by a rapid $(\sim 120 \mathrm{~ms})$ and nearly complete decay of $\mathrm{C}_{\mathrm{m}}$, initially suggesting that endocytosis after stimulation with a single AP is fast, in the range of a few hundred milliseconds (Sun et al. 2002). However, such a rapid and complete $\mathrm{C}_{\mathrm{m}}$ decay was not apparent in other work (Taschenberger et al. 2002) and control experiments in which calyces have been infused with botulinus toxins to block exocytosis have subsequently indicated that the rapid decay in $\mathrm{C}_{\mathrm{m}}$ is not related to exo/endocytosis (Yamashita et al. 2005; Wu et al. 2005). Endocytosis after short AP-equivalent depolarisations is now estimated to occur with a time constant of $10 \mathrm{~s}$ (Yamashita et al. 2005) or $2 \mathrm{~s}$ (Wu et al. 2005); prolonged stimulation leads to the slowing of endocytosis rates by up to $\sim 30 \mathrm{~s}$ (Sun et al. 2002; Yamashita et al. 2005) as observed in hippocampal neurons (Sankaranarayanan and Ryan 2000) by imaging methods with synaptopHlourin (Miesenböck et al. 1998). Endocytosis is blocked by internal perfusion with GTP- $\gamma \mathrm{S}$ or a peptide interrupting the dynamin-amphiphysin interaction, indicating that this membrane retrieval depends on dynamin-1 GTPase activity (Yamashita et al. 2005).

Membrane retrieval at the calyx of Held has also been investigated at the light-microscopic and EM level by studying the uptake of styryl dyes or horseradish peroxidase (HRP; de Lange et al. 2003). Prolonged stimulation at $5 \mathrm{~Hz}$ for $>15$ min leads to de-staining of the styryl dye RH 414 with a time constant of $260 \mathrm{~s}$, from which a recycling pool of $\sim 20,000$ vesicles can be calculated (de Lange et al. 2003) corresponding to $\sim 5-10$ times the number of readily releasable vesicles of 3,000-4,000 (see above). De Lange et al. (2003) also counted the number of RH-414-stained vesicles by using photoconversion and electron microscopy. After strong stimulation with high $\mathrm{K}^{+}$, HRP-labelled endosome-like structures were present, suggesting the activation of bulk membrane retrieval, as previously observed at the neuromuscular junction (Richards et al. 2000). With prolonged $5 \mathrm{~Hz}$ stimulation, however, no sign of bulk membrane retrieval was found and $\sim 5 \%$ of all vesicles were labelled by RH 414. De Lange et al. (2003) conclude that two forms of membrane retrieval exist but that, under physiological stimuli with $5-\mathrm{Hz}$ trains (a frequency similar to the spontaneous firing frequency of these auditory neurons; Kopp-Scheinpflug et al. 2003), the recycling of a limited number of vesicles, most likely without an endosomal intermediate, suffices to guarantee sustained transmitter release at the calyx of Held.

\section{Presynaptic modulation of transmitter release}

The major form of receptor-mediated modulation of transmitter release is via G-protein-coupled depression of presynaptic $\mathrm{Ca}^{2+}$ channels. Modulation of the presynaptic $\mathrm{Ca}^{2+}$ current underlies presynaptic inhibition mediated by metabotropic glutamate receptor (mGluR) and $\gamma$-aminobutyric acid $\left(\mathrm{GABA}_{\mathrm{B}}\right), \mathrm{A} 1$ adenosine and $\alpha 2$ noradrenergic receptors. Intriguingly, other forms of transmitter-mediated modulation occur via direct depolarisation (in the case of glycine), whereas modulation by changes in presynaptic $\mathrm{K}^{+}$ conductance has been tested but has not yet been observed at the calyx. 
Metabotropic glutamate receptors Extensive evidence exists that group III mGluRs (mGluR4,6,7 \& 8) are present at presynaptic sites (Anwyl 1999; Schoepp 2001) and that they act as auto-receptors at many synapses in the CNS. Early reports from synaptic recordings in the MNTB demonstrated depression of calyceal EPSCs on application of the specific group III agonist L-2-amino-4-phosphonobutyrate (L-AP4) and variance analysis revealed that this was attributable to a reduction in the probability of transmitter release (Barnes-Davies and Forsythe 1995). Direct presynaptic recording showed that the mechanism of the reduced release probability involved the inhibition of the $\mathrm{Ca}^{2+}$ current (Fig. 4f) rather than potentiation of a $\mathrm{K}^{+}$ conductance (Takahashi et al. 1996). Because of the power relationship between $\mathrm{Ca}^{2+}$ influx and transmitter release, small changes in presynaptic $\mathrm{Ca}^{2+}$ current have large effects on EPSC amplitude. L-AP4 can depress transmitter release by over $80 \%$ and this action is blocked by the group III antagonist (R,S)-cyclopropyl-4-phosphonophenylglycine (CPPG; von Gersdorff et al. 1997). In the calyx of Held of rat, there is immunocytochemical evidence for mGluR8 (Renden et al. 2005) and mGluR4a (Elezgarai et al. 1999), with mGluR4a immunoreactivity showing a developmental increase, peaking at P9 and then declining to adult levels. However, because of the cascade-catalytic nature of metabotropic signalling pathways, reduced receptor protein may not influence functional signalling or maximal signalling levels, although it might reduce sensitivity (Kenakin 2004). Raising of tonic glutamate levels by blocking glutamate uptake increases mGluR8mediated depression of evoked EPSCs in young animals but, following the opening of the auditory canal, it has less effect and, in P16-18 Sprague-Dawley rats, mGluR agonists cause less depression (around 30\%) than in younger animals ( $>80 \%$; Renden et al. 2005). This suggests a decrease in mGluR function with maturation, although strain differences are possible, since P21 Lister Hooded rats exhibit maintained EPSC depression of $\sim 70 \%$ on the application of L-AP4 (M. Postlethwaite and I.D. Forsythe, unpublished observations). Species differences are also implied by the much lower levels of mGluR modulation observed in mature mice (Renden et al. 2005; C.D. Inchauspe and O.D. Uchitel, personal communication). Intriguingly, several studies, including at the calyx (von Gersdorff et al. 1997; Iwasaki and Takahashi 2001), have noted only small changes in synaptic response on endogenous physiological activation of mGlu autoreceptors by using high-frequency synaptic stimulation. Whereas this result could be interpreted as a failure of synaptically released glutamate to reach presynaptic mGluRs in sufficiently high concentrations, it is also explained by a masking of autoreceptor activation through compensatory increases in available vesicles as the release probability declines because of mGluR activation during the train of synaptic stimuli (Billups et al. 2005). The effect of this increased number of available vesicles and reduced release probability $p$ can be observed as a slowed rate of recovery following high frequency transmission and mGluR activation. Such a masking mechanism may serve to distribute the metabolic load across more release sites, helping to maintain higher frequency transmission and sustaining the dynamic range of transmission across the synapse, without compromising the information contained within the EPSC train.

No evidence for Group II metabotropic receptors has been obtained in direct presynaptic recordings from young rats on application of DCG-IV (Takahashi et al. 1996) but immunohistochemical evidence suggests a shift in expression of Group II receptors in glial cells, during early development, to expression in MNTB neurons on maturation (Elezgarai et al. 2001) implying that physiological studies in older animals may provide further insights. Group I mGluRs have been implicated in mechanisms of retrograde inhibition, involving postsynaptic activation of mGluR 1 triggering the $\mathrm{Ca}^{2+}$-dependent release of endocannabinoids, which subsequently activate calyceal $\mathrm{CB} 1$ receptors and inhibit presynaptic $\mathrm{Ca}^{2+}$ currents (Kushmerick et al. 2004).

$G A B A_{B}$ and glycine $\mathrm{GABA}_{\mathrm{B}}$ receptors are perhaps the most ubiquitous $\mathrm{G}$-protein-coupled presynaptic receptors at glutamatergic synapses (Bowery et al. 2002). Their activation at the calyx of Held causes potent depression of transmitter release (Barnes-Davies and Forsythe 1995) and is mediated by a $G \beta / \gamma$-coupled depression of the presynaptic $\mathrm{Ca}^{2+}$ current (Isaacson 1998; Takahashi et al. 1998) with immunolocalisation suggesting that $\mathrm{G}_{\mathrm{o}}$ subtypes are present at the calyx (Kajikawa et al. 2001). Sakaba and Neher (2003) have shown that, in addition to the wellestablished effect of $\mathrm{GABA}_{\mathrm{B}}$ receptors on presynaptic $\mathrm{Ca}^{2+}$ currents, $\mathrm{GABA}_{\mathrm{B}}$ receptors slow the recovery from synaptic depression (as tested in double-pulse protocols). This slowing of vesicle recruitment after strong release is reversed by intracellular cAMP, indicating that the likely mechanism is an inhibition of adenylate cyclase and a subsequent decrease of cAMP concentration. This signalling pathway involves cAMP-dependent guanosine exchange factor (cAMP-GEF; Ozaki et al. 2000), as determined by a specific cAMP-GEF activator (Sakaba and Neher 2003).

Studies at the chick endbulb synapse suggest that, during high rates of on-going activity, the presynaptic $\mathrm{GABA}_{\mathrm{B}}$ effect may be excitatory in nature and serve to extend the dynamic range of transmission (Brenowitz et al. 1998). There is no evidence of axo-axonic synapses on the calyx (Sätzler et al. 2002) or endbulb of Held (Nicol and Walmsley 2002) and so physiological activation of the 
presynaptic $\mathrm{GABA}_{\mathrm{B}}$ receptors is likely to be attributable to spillover from mixed glycine/GABA synapses, which are present in these brainstem nuclei (Lim et al. 2000; Kim and Kandler 2003). Indeed, a developmental switch from GABA- to glycine-mediated inhibitory transmission in the brainstem (Smith et al. 2000; Nabekura et al. 2004) may underlie a shift in the balance of presynaptic inhibitory drive, since the activation of presynaptic glycine receptors increases transmitter release at the calyx of Held (Turecek and Trussell 2001). There is no known metabotropic glycine receptor but application of glycine activates presynaptic glycine receptor channels (Turecek and Trussell 2002), slightly depolarising the presynaptic membrane potential. Direct depolarisation of the calyx increases resting $\left[\mathrm{Ca}^{2+}\right]_{\mathrm{i}}$ and enhances release in a manner reminiscent of a residual $\mathrm{Ca}^{2+}$ mechanism (Awatramani et al. 2005).

Other metabotropic and presynaptic ionotropic receptors Evidence has been provided for noradrenergic $\alpha 2$ receptor inhibition of the presynaptic $\mathrm{Ca}^{2+}$ current in around half of the calyceal terminals (Leao and von Gersdorff 2002) and for presynaptic adenosine receptors (Barnes-Davies and Forsythe 1995) with A1 receptor depression of presynaptic $\mathrm{Ca}^{2+}$ currents and evoked EPSCs (Kimura et al. 2003; Wong et al. 2006). Although P2X receptors are present on the chick ciliary ganglion calyx (Sun and Stanley 1996) and on non-calyceal inhibitory and excitatory terminals in the MNTB (Watano et al. 2004), no evidence has been found for presynaptic P2X receptors at the calyx of Held. Indeed, the endogenous activation of adenosine $\mathrm{A} 1$ receptors involves the release of adenosine itself, rather than metabolism of ATP by ectonucleotidases, since ATP release cannot be detected by using LuciferinLuciferase bioluminesence at the calyx (Wong et al. 2006). Most recently, the ionotropic glutamate receptor agonist AMPA (Takago et al. 2005) has been found to induce small presynaptic currents and to modulate the presynaptic $\mathrm{Ca}^{2+}$ current via a G-protein-sensitive mechanism.

PKC modulation Phorbol esters have long been known to induce a prolonged increase in transmitter release at synapses (Malenka et al. 1986; Shapira et al. 1987). Phorbol esters activate PKC via binding to their C1domains but recent evidence indicates that their presynaptic mechanism is, at least in part, mediated by binding to the C1-domain of munc-13, a presynaptic vesicle-priming factor (Betz et al. 1998; Rhee et al. 2002). Phorbol ester modulation has been studied at the calyx of Held by using simultaneous pre- and postsynaptic recordings. Hori et al. (1999) have shown that phorbol esters enhance EPSCs without changing mEPSC amplitude, suggesting that the effects are presynaptic. The lack of change in presynaptic voltage-gated $\mathrm{K}^{+}$currents or $\mathrm{Ca}^{2+}$ currents indicates that the potentiation of transmitter release is not mediated by a major change in presynaptic AP waveform or $\mathrm{Ca}^{2+}$ influx, although Lou et al. (2005) have recently found that phorbol ester slightly potentiates presynaptic voltage-gated $\mathrm{Ca}^{2+}$ currents by $\sim 15 \% . \mathrm{C}_{\mathrm{m}}$ measurements have shown that phorbol ester increases release in response to short voltageclamp depolarisations, but not in response to longer depolarisations $(\geq 10 \mathrm{~ms})$, which by themselves empty the pool of readily releasable vesicles ( $\mathrm{Wu}$ and $\mathrm{Wu} 2001$ ). Using presynaptic $\mathrm{Ca}^{2+}$ uncaging and paired pre- and postsynaptic recordings, Lou et al. (2005) have shown that phorbol esters increase the $\mathrm{Ca}^{2+}$ sensitivity of vesicle fusion as probed by $\mathrm{Ca}^{2+}$ uncaging. Thus, there is good agreement that phorbol esters increase the $\mathrm{Ca}^{2+}$ sensitivity of vesicle fusion at the calyx of Held without increasing the number of readily releasable vesicles. There is immunocytochemical evidence that phorbol esters act through the PKC- $\varepsilon$ isoform (Saitoh et al. 2001) but an involvement of munc-13 has also been reported (Hori et al. 1999).

\section{Concluding remarks and future perspectives}

We now possess perhaps a more detailed understanding of the ionic and biophysical basis of transmission at the calyx of Held than for any other synapse. Indeed, beyond the technical feat of making presynaptic recordings, it is the wealth of detailed knowledge that will promote further studies of transmitter release at this synapse and permit the exploration of how specific proteins participate in regulating specific steps of transmitter release.

The main strength of the calyx of the Held has been the accessibility of its presynaptic terminal to patch-clamp recordings. This has allowed various groups to study whether changes in presynaptic excitability, AP waveform or $\mathrm{Ca}^{2+}$ currents underlie presynaptic forms of short-term plasticity and the modulation of transmitter release. These studies have established that the activation of a surprising wealth of presynaptic metabotropic receptors (mGluRs, $\mathrm{GABA}_{\mathrm{B}}$, adenosine and noradrenalin) mostly act via a direct G-protein-coupled reduction of voltage-gated $\mathrm{Ca}^{2+}$ currents, without affecting the presynaptic AP waveform or presynaptic $\mathrm{K}^{+}$currents. Short-term depression is accompanied, but not mediated, by changes in presynaptic AP waveform but can be mediated in part by $\mathrm{Ca}^{2+}$-dependent inactivation of presynaptic $\mathrm{Ca}^{2+}$ currents. These studies have re-emphasised that small changes in $\mathrm{Ca}^{2+}$ influx can potently modulate transmitter release, because of the highpower relationship between $\mathrm{Ca}^{2+}$ and release.

The accessibility of the presynaptic calyx nerve terminal has proven crucial to determining mechanisms underlying $\mathrm{Ca}^{2+}$ - 
evoked transmitter release. $\mathrm{Ca}^{2+}$ uncaging in the nerve terminal shows a surprisingly high $\mathrm{Ca}^{2+}$ sensitivity and cooperativity of release, with an exponent of 4-5. These estimates of the $\mathrm{Ca}^{2+}$ sensitivity of vesicle fusion have constrained parameters for realistic computational models of $\mathrm{Ca}^{2+}$-secretion-coupling in nerve terminals (Meinrenken et al. 2002). The high $\mathrm{Ca}^{2+}$ cooperativity and the finding that multiple $\mathrm{Ca}^{2+}$ channels control the release of a given vesicle (at least in young animals; see Fedchyshyn and Wang 2005) permit highly efficient control of transmitter release. The ability to voltage-clamp both pre- and postsynaptic compartments, together with EPSC deconvolution, has given insights into the factors that control the time-course of transmitter release (Felmy et al. 2003a) and revealed the surprisingly large number of readily releasable vesicles $(\sim 3,000-4,000)$ compared with the modest number of quanta released by a single AP ("only" 150-250). These findings demonstrate that not all vesicles have the same release probability; this heterogeneity influences the rates of vesicle pool depletion during prolonged high-frequency trains. Taken together, our knowledge of the structure, biophysics and physiology of this synapse are increasingly detailed and are beginning to be built into computational models of transmission (Trommershäuser et al. 2003; Graham et al. 2004), which have been refined by reiterative modelling and experimental testing.

As with every experimental model, there are also limitations, which future work may overcome. Dialysis of the terminal restricts studies of ion channel modulation and presynaptic plasticity, since it is impossible to add all potential signalling precursors to our patch pipette solutions, and there is an important need to perfect perforated patch recording from the calyx. It has been difficult to perturb the calyx of Held at the molecular level and therefore to relate presynaptic function to specific molecules. Acute over-expression of proteins is not possible in the slice preparation, because of the lack/slow rate of protein synthesis in isolated terminals and because most calyceal axons are severed during the slicing process. Organotypic cultures of the auditory brainstem are possible (Lohmann et al. 1998) but there are no reports of the survival of calyceal terminals in slice culture. Transgenic mice with knockedout or mutated presynaptic proteins have been studied (Fernández-Chacón et al. 2004; Pang et al. 2006) but an analysis of perinatally lethal mice is impossible because the optimal age window (P6-P14) for functional studies is not reached. In-vivo virus-mediated over-expression of proteins may provide a suitable vehicle in the calyx of Held (Wimmer et al. 2004) and should in principle allow the application of small interfering RNA (siRNA) silencing of gene expression (He and Hannon 2004). The application of virus-mediated over-expression and siRNA-mediated knock-down approaches at the calyx of Held will vastly expand the usefulness of this preparation.

Development of cell-type-specific knock-out or knock-in mice would also be highly desirable. Unfortunately, promotors specifically active in selective types of neurons have only been identified in a few cases (Tsien et al. 1996; Barski et al. 2000; Díez-Garcia et al. 2005). The need for specific promotors will draw the attention to the characterisation of bushy cell subtypes in the aVCN. Calyces of Held are thought to arise from globular bushy cells but the presynaptic neuron population might be heterogeneous both with respect to localisation and gene expression and we know little about the specific genes expressed in these cells. Although gene expression analyses have recently been performed in auditory brainstem nuclei (Cho et al. 2001; Koehl et al. 2004; Harris et al. 2005), the ventral cochlear nucleus is composed of many cell types (Oertel 1999) and so the identification of the bushy cell subtypes that give rise to the calyx and the study of their selective gene expression profiles will be crucial. Combined molecular, anatomical and physiological studies will also be helpful in identifying the molecules that play a role in establishing the precise synaptic connectivity of the auditory system (Cramer et al. 2004).

Acknowledgements The work in the author's laboratories has been supported by the Deutsche Forschungsgemeinschaft (SFB-406, Schn 451/4-1 and a Heisenberg fellowship to R.S.), and the Wellcome Trust, BBSRC and the MRC (to I.D.F.).

\section{References}

Aldrich RW (2001) Fifty years of inactivation. Nature 411:643-644 Anwyl R (1999) Metabotropic glutamate receptors: electrophysiological properties and role in plasticity. Brain Res Brain Res Rev 29:83-120

Auger C, Kondo S, Marty A (1998) Multivesicular release at single functional synaptic sites in cerebellar stellate and basket cells. J Neurosci 18:4532-4547

Augustine GJ, Charlton MP, Smith SJ (1985) Calcium entry and transmitter release at voltage-clamped nerve terminals of squid. J Physiol (Lond) 369:163-181

Awatrami GB, Turecek R, Trussell L (2004) Inhibitory control at a synaptic relay. J Neurosci 24:2643-2647

Awatramani GB, Price GD, Trussell LO (2005) Modulation of transmitter release by presynaptic resting potential and background calcium levels. Neuron 48:109-121

Bal R, Oertel D (2001) Potassium currents in octopus cells of the mammalian cochlear nucleus. J Neurophysiol 86:2299-2311

Banks MI, Smith PH (1992) Intracellular recordings from neurobiotinlabeled cells in brain slices of the rat medial nucleus of the trapezoid body. J Neurosci 12:2819-2837

Banks MI, Pearce RA, Smith PH (1993) Hyperpolarization-activated cation current (Ih) in neurons of the medial nucleus of the trapezoid body: voltage-clamp analysis and enhancement by norepinephrine and cAMP suggest a modulatory mechanism in the auditory brain stem. J Neurophysiol 70:1420-1432 
Barnes-Davies M, Forsythe ID (1995) Pre- and postsynaptic glutamate receptors at a giant excitatory synapse in rat auditory brainstem slices. J Physiol (Lond) 488:387-406

Barrett EF, Barrett JN (1982) Intracellular recording from vertebrate myelinated axons: mechanism of the depolarizing afterpotential. J Physiol (Lond) 323:117-144

Barski JJ, Dethleffsen K, Meyer M (2000) Cre recombinase expression in cerebellar Purkinje cells. Genesis 28:93-98

Beaumont V, Zucker RS (2000) Enhancement of synaptic transmission by cyclic AMP modulation of presynaptic Ih channels. Nat Neurosci 3:133-141

Bergsman JB, De Camilli P, McCormick DA (2004) Multiple large inputs to principal cells in the mouse medial nucleus of the trapezoid body. J Neurophysiol 92:545-552

Betz A, Ashery U, Rickmann M, Augustin I, Neher E, Südhof TC, Rettig J, Brose N (1998) Munc13-1 is a presynaptic phorbol ester receptor that enhances neurotransmitter release. Neuron $21: 123-136$

Bhattacharjee A, Kaczmarek LK (2005) For $\mathrm{K}^{+}$channels, $\mathrm{Na}^{+}$is the new $\mathrm{Ca}^{2+}$. Trends Neurosci 28:422-428

Billups B, Forsythe ID (2002) Presynaptic mitochondrial calcium sequestration influences transmission at mammalian central synapses. J Neurosci 22:5840-5847

Billups B, Graham BP, Wong AY, Forsythe ID (2005) Unmasking group III metabotropic glutamate autoreceptor function at excitatory synapses in the rat CNS. J Physiol (Lond) 565:885896

Blatchley BJ, Cooper WA, Coleman JR (1987) Development of auditory brainstem response to tone pip stimuli in the rat. Brain Res 429:75-84

Bollmann JH, Sakmann B (2005) Control of synaptic strength and timing by the release-site $\mathrm{Ca}^{2+}$ signal. Nat Neurosci 8:426-434

Bollmann JH, Sakmann B, Borst JGG (2000) Calcium sensitivity of glutamate release in a calyx-type terminal. Science 289:953-957

Borst JGG, Sakmann B (1996) Calcium influx and transmitter release in a fast CNS synapse. Nature 383:431-434

Borst JGG, Sakmann B (1998a) Facilitation of presynaptic calcium currents in the rat brainstem. J Physiol (Lond) 513:149-155

Borst JGG, Sakmann B (1998b) Calcium current during a single action potential in a large presynaptic terminal of the rat brainstem. J Physiol (Lond) 506:143-157

Borst JGG, Sakmann B (1999) Effect of changes in action potential shape on calcium currents and transmitter release in a calyx-type synapse of the rat auditory brainstem. Philos Trans R Soc Lond Biol 354:347-355

Borst JGG, Helmchen F, Sakmann B (1995) Pre- and postsynaptic whole-cell recordings in the medial nucleus of the trapezoid body of the rat. J Physiol (Lond) 489:825-840

Bowery NG, Bettler B, Froestl W, Gallagher JP, Marshall F, Raiteri M, Bonner TI, Enna SJ (2002) International Union of Pharmacology. XXXIII. Mammalian gamma-aminobutyric acid(B) receptors: structure and function. Pharmacol Rev 54:247-264

Brand A, Behrend O, Marquardt T, McAlpine D, Grothe B (2002) Precise inhibition is essential for microsecond interaural time difference coding. Nature 417:543-547

Brenowitz S, David J, Trussell L (1998) Enhancement of synaptic efficacy by presynaptic $\mathrm{GABA}_{\mathrm{B}}$ receptors. Neuron 20:135-141

Brew HM, Forsythe ID (1995) Two voltage-dependent $\mathrm{K}^{+}$conductances with complementary functions in postsynaptic integration at a central auditory synapse. J Neurosci 15:8011-8022

Caldwell JH, Schaller KL, Lasher RS, Peles E, Levinson SR (2000) Sodium channel $\mathrm{Na}(\mathrm{v}) 1.6$ is localized at nodes of Ranvier, dendrites, and synapses. Proc Natl Acad Sci USA 97:5616-5620
Catterall WA, Goldin AL, Waxman SG (2005) International Union of Pharmacology. XLVII. Nomenclature and structure-function relationships of voltage-gated sodium channels. Pharmacol Rev 57:397-409

Chad JE, Eckert R (1984) Calcium domains associated with individual channels can account for anomalous voltage relations of $\mathrm{Ca}$ dependent responses. Biophys J 45:993-999

Chevaleyre V, Castillo PE (2002) Assessing the role of Ih channels in synaptic transmission and mossy fiber LTP. Proc Natl Acad Sci USA 99:9538-9543

Cho Y, Gong T-WL, Stöver T, Lomax MI, Altschuler RA (2001) Gene expression profiles of the rat cochlea, chochlear nucleus, and inferior colliculus. JARO 3:54-67

Chuhma N, Ohmori H (1998) Postnatal development of phase-locked high-fidelity synaptic transmission in the medial nucleus of the trapezoid body of the rat. J Neurosci 18:512-520

Coetzee WA, Amarillo Y, Chiu J, Chow A, Lau D, McCormack T, Moreno H, Nadal MS, Ozaita A, Pountney D, Saganich M, VegaSaenz de Miera E, Rudy B (1999) Molecular diversity of $\mathrm{K}^{+}$ channels. Ann N Y Acad Sci 868:233-285

Cramer KS, Bermingham-McDonogh O, Krull CE, Rubel EW (2004) EphA4 signaling promotes axon segregation in the developing auditory system. Dev Biol 269:26-35

Cuttle MF, Tsujimoto T, Forsythe ID, Takahashi T (1998) Facilitation of the presynaptic calcium current at an auditory synapse in rat brainstem. J Physiol (Lond) 512:723-729

Cuttle MF, Rusznák Z, Wong AYC, Owens S, Forsythe ID (2001) Modulation of a presynaptic hyperpolarization-activated cationic current (Ih) at an excitatory synaptic terminal in the rat auditory brainstem. J Physiol (Lond) 534:733-744

Day M, Carr DB, Ulrich S, Ilijic E, Tkatch T, Surmeier DJ (2005) Dendritic excitability of mouse frontal cortex pyramidal neurons is shaped by the interaction among $\mathrm{HCN}$, Kir2, and Kleak channels. J Neurosci 25:8776-8787

De Lange RPJ, Roos ADG de, Borst JGG (2003) Two modes of vesicle recycling in the rat calyx of Held. J Neurosci 23:10164-10173

Delmas P, Brown DA (2005) Pathways modulating neural KCNQ/M (Kv7) potassium channels. Nat Rev Neurosci 6:850-862

DeMaria CD, Soong TW, Alseikhan BA, Alvania RS, Yue DT (2001) Calmodulin bifurcates the local $\mathrm{Ca}^{2+}$ signal that modulates $\mathrm{P} / \mathrm{Q}-$ type $\mathrm{Ca}^{2+}$ channels. Nature 411:484-489

Díez-Garcia J, Matsushita S, Mutoh H, Nakai J, Ohkura M, Yokoyama J, Dimitrov D, Knöpfel T (2005) Activation of cerebellar parallel fibers monitored in transgenic mice expressing a fluorescent $\mathrm{Ca}^{2+}$ indicator protein. Eur J Neurosci 22:627-635

DiGregorio DA, Nusser Z, Silver RA (2002) Spillover of glutamate onto synaptic AMPA receptors enhances fast transmission at a cerebellar synapse. Neuron 35:521-533

Dodson PD, Barker MC, Forsythe ID (2002) Two heteromeric Kv1 potassium channels differentially regulate action potential firing. J Neurosci 22:6953-6961

Dodson PD, Billups B, Rusznak Z, Szucs G, Barker MC, Forsythe ID (2003) Presynaptic rat Kv1.2 channels suppress synaptic terminal hyperexcitability following action potential invasion. J Physiol (Lond) 550:27-33

Doughty JM, Barnes-Davies M, Rusznak Z, Harasztosi C, Forsythe ID (1998) Contrasting $\mathrm{Ca}^{2+}$ channel subtypes at cell bodies and synaptic terminals of rat anterioventral cochlear bushy neurones. J Physiol (Lond) 512:365-376

Elezgarai I, Benitez R, Mateos JM, Lazaro E, Osorio A, Azkue JJ, Bilbao A, Lingenhoehl K, Van Der Putten H, Hampson DR, Kuhn R, Knopfel T, Grandes P (1999) Developmental expression of the group III metabotropic glutamate receptor mGluR4a in the medial nucleus of the trapezoid body of the rat. J Comp Neurol 411:431-440 
Elezgarai I, Bilbao A, Mateos JM, Azkue JJ, Benitez R, Osorio A, Diez J, Puente N, Donate-Oliver F, Grandes P (2001) Group II metabotropic glutamate receptors are differentially expressed in the medial nucleus of the trapezoid body in the developing and adult rat. Neurosci 104:487-498

Elezgarai I, Diez J, Puente N, Azkue JJ, Benitez R, Bilbao A, Knopfel T, Donate-Oliver F, Grandes P (2003) Subcellular localization of the voltage-dependent potassium channel $\mathrm{Kv} 3.1 \mathrm{~b}$ in postnatal and adult rat medial nucleus of the trapezoid body. Neurosci 118:889-898

Elmquist D, Quastel DMJ (1965) A quantitative study of end-plate potentials in isolated human muscle. J Physiol (Lond) 178:505-529

Engel D, Jonas P (2005) Presynaptic action potential amplification by voltage-gated $\mathrm{Na}^{+}$channels in hippocampal mossy fiber boutons. Neuron 45:405-417

Fedchyshyn MJ, Wang L-Y (2005) Developmental transformation of the release modality at the calyx of Held synapse. J Neurosci 25:4131-4140

Felmy F, Schneggenburger R (2004) Developmental expression of the $\mathrm{Ca}^{2+}$-binding proteins calretinin and parvalbumin at the calyx of Held of rats and mice. Eur J Neurosci 20:1473-1482

Felmy F, Neher E, Schneggenburger R (2003a) The timing of phasic transmitter release is $\mathrm{Ca}^{2+}$ dependent and lacks a direct influence of presynaptic membrane potential. Proc Natl Acad Sci USA 100:15200-15205

Felmy F, Neher E, Schneggenburger R (2003b) Probing the intracellular calcium sensitivity of transmitter release during synaptic facilitation. Neuron 37:801-811

Fernández-Chacón R, Konigstorfer A, Gerber SH, Garcia J, Matos MF, Stevens CF, Brose N, Rizo J, Rosenmund C, Sudhof TC (2001) Synaptotagmin I functions as a calcium regulator of release probability. Nature 410:41-49

Fernández-Chacón R, Wölfel M, Nishimune H, Tabares L, Schmitz F, Castellano-Muñoz M, Rosenmund C, Montesinos ML, Sanes JR, Schneggenburger R, Südhof TC (2004) The synaptic vesicle protein CSP $\alpha$ prevents presynaptic degeneration. Neuron 42:237-251

Forsythe ID (1994) Direct patch recording from identified presynaptic terminals mediating glutamatergic EPSCs in the rat CNS, in vitro. J Physiol (Lond) 479:381-387

Forsythe ID, Barnes-Davies M (1993) The binaural auditory pathway: exitatory amino acid receptors mediate dual timecourse excitatory postsynaptic currents in the rat medial nucleus of the trapezoid body. Proc R Soc Lond [Biol] 251:151-157

Forsythe ID, Tsujimoto T, Barnes-Davies M, Cuttle MF, Takahashi T (1998) Inactivation of presynaptic calcium current contributes to synaptic depression at a fast central synapse. Neuron 20:797-807

Friauf E, Ostwald J (1988) Divergent projections of physiologically characterized rat ventral cochlear nucleus neurons as shown by intra-axonal injection of horseradish peroxidase. Exp Brain Res $73: 263-284$

Futai K, Okada M, Matsuyama K, Takahashi T (2001) High-fidelity transmission acquired via a developmental decrease in NMDA receptor expression at an auditory synapse. J Neurosci 21:3342-3349

Gardner SM, Trussell LO, Oertel D (1999) Time course and permeation of synaptic AMPA receptors in cochlear nuclear neurons correlate with input. J Neurosci 19:8721-8729

Geal-Dor M, Freeman S, Li G, Sohmer H (1993) Development of hearing in neonatal rats: air and bone conducted ABR thresholds. Hear Res 69:236-242

Geiger JR, Jonas P (2000) Dynamic control of presynaptic $\mathrm{Ca}^{2+}$ inflow by fast-inactivating $\mathrm{K}^{+}$channels in hippocampal mossy fiber boutons. Neuron 28:927-939

Geiger JRP, Melcher T, Koh D-S, Sakmann B, Seeburg PH, Jonas P, Monyer H (1995) Relative abundance of subunit mRNAs determines gating and $\mathrm{Ca}^{2+}$-permeability of AMPA receptors in principal neurons and interneurons in rat CNS. Neuron 15:193-204

Geppert M, Goda Y, Hammer RE, Li C, Rosahl TW, Stevens CF, Südhof TC (1994) Synaptotagmin I: a major $\mathrm{Ca}^{2+}$ sensor for transmitter release at a central synapse. Cell 79:717-727

Goldstein SA, Bockenhauer D, O'Kelly I, Zilberberg N (2001) Potassium leak channels and the KCNK family of two-P-domain subunits. Nat Rev Neurosci 2:175-184

Graham BP, Wong AY, Forsythe ID (2004) A multicomponent model of depression at the calyx of Held. Neurocomputing 58-60: 449-454

Grandes P, Streit P (1989) Glutamate-like immunoreactivity in the calyces of Held. J Neurocytol 18:685-693

Habets RLP, Borst JGG (2005) Post-tetanic potentiation in the rat calyx of Held synapse. J Physiol (Lond) 564:173-187

Hamann M, Billups B, Forsythe ID (2003) Non-calyceal excitatory inputs mediate low fidelity synaptic transmission in rat auditory brainstem slices. Eur J Neurosci 18:2899-2902

Harris JA, Hardie NA, Bermingham-McDonogh O, Rubel EW (2005) Gene expression differences over a critical period of afferentdependent neuron survival in the mouse auditory brainstem. J Comp Neurol 493:460-474

Harrison JM, Irving R (1966) Ascending connections of the anterior ventral cochlear nucleus in the rat. J Comp Neurol 126:51-64

He L, Hannon GJ (2004) MicroRNAs: small RNAs with a big role in gene regulation. Nat Rev Genet 5:522-532

Held H (1893) Die zentrale Gehörleitung. Arch Anat Physiol Anat Abtheil 17:201-248

Helmchen F, Borst JGG, Sakmann B (1997) Calcium dynamics associated with a single action potential in a CNS presynaptic terminal. Biophys J 72:1458-1471

Hoffpauir BK, Grimes JL, Mathers PH, Spirou GA (2006) Synaptogenesis of the calyx of Held: Rapid onset of function and one-to-one morphological innervation. J Neurosci 26: 5511-5523

Hori T, Takai Y, Takahashi T (1999) Presynaptic mechanism for phorbol ester-induced synaptic potentiation. J Neurosci 19:7262-7267

Hu H, Vervaeke K, Storm JF (2002) Two forms of electrical resonance at theta frequencies, generated by M-current, h-current and persistent $\mathrm{Na}^{+}$current in rat hippocampal pyramidal cells. J Physiol (Lond) 545:783-805

Humeau Y, Doussau F, Grant NJ, Poulain B (2000) How botulinum and tetanus neurotoxins block neurotransmitter release. Biochemie 82:427-446

Inchauspe CG, Martini FJ, Forsythe ID, Uchitel OD (2004) Functional compensation of $\mathrm{P} / \mathrm{Q}$ by N-type channels blocks short-term plasticity at the calyx of Held presynaptic terminal. J Neuroscience 24:10379-10383

Isaacson JS (1998) GABA $_{B}$ receptor-mediated modulation of presynaptic currents and excitatory transmission at a fast central synapse. J Neurophysiol 80:1571-1576

Isaacson J, Walmsley B (1995) Receptors underlying excitatory synaptic transmission in slices of the rat anteroventral cochlear nucleus. J Neurophysiol 73:964-973

Ishikawa T, Sahara Y, Takahashi T (2002) A single packet of transmitter does not saturate postsynaptic glutamate receptors. Neuron 34:613-621

Ishikawa T, Nakamura Y, Saitoh N, Li WB, Iwasaki S, Takahashi $\mathrm{T}$ (2003) Distinct roles of Kv1 and Kv3 potassium channels at the calyx of Held presynaptic terminal. J Neurosci 23:10445-10453

Ishikawa T, Kaneko M, Shin H-S, Takahashi T (2005) Presynaptic N-type and $\mathrm{P} / \mathrm{Q}$-type $\mathrm{Ca}^{2+}$-channels mediating synaptic transmission at the calyx of Held of mice. J Physiol (Lond) 568:199-209 
Iwasaki S, Takahashi T (1998) Developmental changes in calcium channel types mediating synaptic transmission in rat auditory brainstem. J Physiol (Lond) 509:419-423

Iwasaki S, Takahashi T (2001) Developmental regulation of transmitter release at the calyx of Held in rat auditory brainstem. J Physiol (Lond) 534:861-871

Iwasaki S, Momiyama A, Uchitel OD, Takahashi T (2000) Developmental changes in calcium channel types mediating central synaptic transmission. J Neurosci 20:59-65

Jackson M, Konnerth A, Augustine G (1991) Action potential broadening and frequency-dependent facilitation of calcium signals in pituitary nerve terminals. Proc Natl Acad Sci USA 88:380-384

Jean-Baptiste M, Morest DK (1975) Transneuronal changes of synaptic endings and nuclear chromatin in the trapezoid body following cochlear ablations in cats. J Comp Neurol 162:111-134

Jerng HH, Pfaffinger PJ, Covarrubias M (2004) Molecular physiology and modulation of somatodendritic A-type potassium channels. Mol Cell Neurosci 27:343-369

Joris PX, Smith PH, Yin TCT (1998) Coincidence detection in the auditory system: 50 years after Jeffress. Neuron 21:1235-1238

Joshi I, Wang L-Y (2002) Developmental profiles of glutamate receptors and synaptic transmission at a single synapse in the mouse auditory brainstem. J Physiol (Lond) 540:861-873

Joshi I, Shokralla S, Titis P, Wang L-Y (2004) The role of AMPA receptor gating in the development of high-fidelity neurotransmission at the calyx of Held. J Neuroscience 24:183-196

Kaczmarek LK, Bhattacharjee A, Desai R, Gan L, Song P, Hehn CA von, Whim MD, Yang B (2005) Regulation of the timing of MNTB neurons by short-term and long-term modulation of potassium channels. Hear Res 206:133-145

Kajikawa Y, Saitoh N, Takahashi T (2001) GTP-binding protein beta gamma subunits mediate presynaptic calcium current inhibition by GABA(B) receptor. Proc Natl Acad Sci USA 98:8054-8058

Kandler K, Friauf E (1993) Pre- and postnatal development of efferent connections of the cochlear nucleus in the rat. J Comp Neurol 328:161-184

Karschin C, Wischmeyer E, Preisig-Muller R, Rajan S, Derst C, Grzeschik KH, Daut J, Karschin A (2001) Expression pattern in brain of TASK-1, TASK-3, and a tandem pore domain $\mathrm{K}(+)$ channel subunit, TASK-5, associated with the central auditory nervous system. Mol Cell Neurosci 18:632-648

Katz B (1969) The release of neural transmitter substances. Liverpool University Press, Liverpool

Katz E, Ferro PA, Cherksey BD, Sugimori M, Llinas R, Uchitel OD (1995) Effects of $\mathrm{Ca}^{2+}$ channel blockers on transmitter release and presynaptic currents at the frog neuromuscular junction. J Physiol (Lond) 486:695-706

Kenakin T (2004) Principles: receptor theory in pharmacology. Trends Pharmacol Sci 25:186-192

Kim G, Kandler K (2003) Elimination and strengthening of glycinergic/GABAergic connections during tonotopic map formation. Nat Neurosci 6:282-290

Kim M-H, Korogod N, Schneggenburger R, Ho W-K, Lee S-H (2005) Interplay between $\mathrm{Na}^{+} / \mathrm{Ca}^{2+}$ exchangers and mitochondria in $\mathrm{Ca}^{2+}$ clearance at the calyx of Held. J Neurosci 25:6057-6065

Kimura M, Saitoh N, Takahashi T (2003) Adenosine A(1) receptormediated presynaptic inhibition at the calyx of Held of immature rats. J Physiol (Lond) 553:415-426

Koch U, Braun M, Kapfer C, Grothe B (2004) Distribution of HCN1 and $\mathrm{HCN} 2$ in rat auditory brainstem nuclei. Eur J Neurosci 20:79-91

Koehl A, Schmidt N, Rieger A, Pilgram SM, Letunic I, Bork P, Soto F, Friauf E, Nothwang HG (2004) Gene expression profiling of the rat superior olivary complex using serial analysis of gene expression. Eur J Neurosci 20:3244-3258

Koike-Tani M, Saitoh N, Takahashi T (2005) Mechanisms underlying developmental speeding in AMPA-EPSC decay time at the calyx of Held. J Neurosci 25:199-207

Kopp-Scheinpflug C, Fuchs K, Lippe WR, Tempel BL, Rübsamen R (2003) Decreased temporal precision of auditory signaling in Kcna1-null mice: an electrophysiological study in vivo. J Neuroscience 23:9199-9207

Korn H, Triller A, Mallet A, Faber DS (1981) Fluctuating responses at a central synapse: $n$ of binomial fit predicts number of stained presynaptic boutons. Science 213:898-901

Korogod N, Lou X, Schneggenburger R (2005) Presynaptic $\mathrm{Ca}^{2+}$ requirements and developmental regulation of posttetanic potentiation at the calyx of Held. J Neurosci 25:5127-5137

Kushmerick C, Price GD, Taschenberger H, Puente N, Renden R, Wadiche JI, Duvoisin R, Grandes P, Gersdorff H von (2004) Retroinhibition of presynaptic $\mathrm{Ca}^{2+}$ currents by endocannabinoids released via postsynaptic mGluR activation at a calyx synapse. J Neurosci 24:5955-5965

Kushmerick C, Renden R, Gersdorff H von (2006) Physiological temperatures reduce the rate of vesicle pool depletion and shortterm depression via an accelaration of vesicle recruitment. J Neurosci 26:1366-1377

Kuwabara N, DiCaprio RA, Zook JM (1991) Afferents to the medial nucleus of the trapezoid body and their collateral projections. J Comp Neurol 314:684-706

Leao RM, von Gersdorff H (2002) Noradrenaline increases highfrequency firing at the calyx of Held synapse during development by inhibiting glutamate release. J Neurophysiol 87:2297-2306

Leao RM, Kushmerick C, Pinaud R, Renden R, Li GL, Taschenberger H, Spirou G, Levinson SR, Gersdorff H von (2005) Presynaptic $\mathrm{Na}^{+}$channels: locus, development, and recovery from inactivation at a high-fidelity synapse. J Neurosci 25: 3724-3738

Lemos JR, Nordmann JJ (1986) Ionic channels and hormone release from peptidergic nerve terminals. J Exp Biol 124:53-72

Lenn NJ, Reese TS (1966) The fine structure of nerve endings in the nucleus of the trapezoid body and the ventral cochlear nucleus. Am J Anat 118:375-390

Li J, Zagotta WN, Lester HA (1997) Cyclic nucleotide-gated channels: structural basis of ligand efficacy and allosteric modulation. Q Rev Biophys 30:177-193

Liley AW, North KAK (1953) An electrical investigation of effects of repetitive stimulation on mammalian neuromuscular junction. J Neurophysiol 16:509-527

Lim R, Alvarez FJ, Walmsley B (2000) GABA mediates presynaptic inhibition at glycinergic synapses in a rat auditory brainstem nucleus. J Physiol (Lond) 525:447-459

Llinas R, Blinks JR, Nicholson C (1972) Calcium transient in presynaptic terminal of squid giant synapse: detection with aequorin. Science 176:1127-1129

Lohmann C, Ilic V, Friauf E (1998) Development of a topographically organized auditory network in slice culture is calcium dependent. J Neurobiol 34:97-112

Lorente de No R (1981) The primary acoustic nuclei. Raven, New York

Lou X, Scheuss V, Schneggenburger R (2005) Allosteric modulation of the presynaptic $\mathrm{Ca}^{2+}$ sensor for vesicle fusion. Nature 435:497-501

Macica CM, Kaczmarek LK (2001) Casein kinase 2 determines the voltage dependence of the Kv3.1 channel in auditory neurons and transfected cells. J Neurosci 21:1160-1168

Macica CM, Hehn CA von, Wang LY, Ho CS, Yokoyama S, Joho RH, Kaczmarek LK (2003) Modulation of the kv3.1b potassium channel isoform adjusts the fidelity of the firing pattern of auditory neurons. J Neurosci 23:1133-1141 
Malenka RC, Madison DV, Nicoll RA (1986) Potentiation of synaptic transmission in the hippocampus by phorbol ester. Nature 321:175-177

Martin AR, Pilar G (1963) Dual mode of synaptic transmission in the avian ciliary ganglion. J Physiol (Lond) 168:443-463

Matveev V, Wang X-J (2000) Implications of all-or-none synaptic transmission and short-term depression beyond vesicle depletion: a computational study. J Neurosci 20:1575-1588

Meinrenken C, Borst JGG, Sakmann B (2002) Calcium secretion coupling at calyx of Held governed by nonuniform channelvesicle topography. J Neurosci 22:1648-1667

Mellor J, Nicoll RA, Schmitz D (2002) Mediation of hippocampal mossy fiber long-term potentiation by presynaptic Ih channels. Science 295:143-147

Meyer AC, Neher E, Schneggenburger R (2001) Estimation of quantal size and number of functional active zones at the calyx of Held synapse by nonstationary EPSC variance analysis. J Neurosci 21:7889-7900

Miesenböck G, Angelis DA de, Rothman JE (1998) Visualizing secretion and synaptic transmission with $\mathrm{pH}$-sensitive green fluorescent proteins. Nature 349:192-195

Misonou H, Menegola M, Buchwalder L, Park EW, Meredith A, Rhodes KJ, Aldrich RW, Trimmer JS (2006) Immunolocalization of the $\mathrm{Ca}^{2+}$-activated $\mathrm{K}^{+}$channel Slo1 in axons and nerve terminals of mammalian brain and cultured neurons. J Comp Neurol 496:289-302

Morest KD (1968) The growth of synaptic endings in the mammalian brain: a study of the calyces of the trapezoid body. Z Anat Entwickl 127:201-220

Moulder KL, Mennerick S (2005) Reluctant vesicles contribute to the total readily releasable pool in glutamatergic hippocampal neurons. J Neurosci 25:3842-3850

Nabekura J, Katsurabayashi S, Kakazu Y, Shibata S, Matsubara A, Jinno S, Mizoguchi Y, Sasaki A, Ishibashi H (2004) Developmental switch from GABA to glycine release in single central synaptic terminals. Nat Neurosci 7:17-23

Nakajima Y (1971) Fine structure of the medial nucleus of the trapezoid body of the bat with special reference to two types of synaptic endings. J Cell Biol 50:121-134

Naraghi M, Müller TH, Neher E (1998) Two-dimensional determination of the cellular $\mathrm{Ca}^{2+}$ binding in bovine chromaffin cells. Biophys J 75:1635-1647

Neher E, Marty A (1982) Discrete changes of cell membrane capacitance observed under conditions of enhanced secretion in bovine adrenal chromaffin cells. Proc Natl Acad Sci USA 79:6712-6716

Neher E, Sakaba T (2001) Combining deconvolution and noise analysis for the estimation of transmitter release rates at the calyx of Held. J Neurosci 21:444-461

Nicholls DG, Sihra TS (1986) Synaptosomes possess an exocytotic pool of glutamate. Nature 321:772-773

Nicol MJ, Walmsley B (2002) Ultrastructural basis of synaptic transmission between endbulbs of Held and bushy cells in the rat cochlear nucleus. J Physiol (Lond) 539:713-723

Oertel D (1999) The role of timing in the brain stem auditory nuclei of vertebrates. Annu Rev Physiol 61:497-519

Otis T, Zhang S, Trussell LO (1996) Direct measurement of AMPA receptor desensitization induced by glutamatergic synaptic transmission. J Neurosci 16:7496-7504

Ozaki N, Shibasaki T, Kashima Y, Miki T, Takahashi K, Ueno H, Sunaga Y, Yano H, Matsuura Y, Iwanaga T, Takai Y, Seino S (2000) cAMP-GEF II is a direct target of cAMP in regulated exocytosis. Nat Cell Biol 2:805-811

Pang ZP, Sun JY, Rizo J, Maximov A, Südhof TC (2006) Genetic analysis of synaptotagmin 2 in spontaneous and $\mathrm{Ca}^{2+}$-triggered neurotransmitter release. EMBO J 25:2039-2050
Quastel DMJ (1997) The binomial model in fluctuation analysis of quantal neurotransmitter release. Biophys J 72:728-753

Ramón y Cajal S (1972) Histologie du système nerveux de l'homme et des vertébrés. Instituto Ramón y Cajal, Madrid

Rasband MN, Shrager P (2000) Ion channel sequestration in central nervous system axons. J Physiol (Lond) 525:63-73

Renden R, Taschenberger H, Puente N, Rusakov DA, Duvoisin R, Wang LY, Lehre KP, Gersdorff H von (2005) Glutamate transporter studies reveal the pruning of metabotropic glutamate receptors and absence of AMPA receptor desensitization at mature calyx of Held synapses. J Neurosci 25:8482-8497

Rhee J-S, Betz A, Pyott S, Reim K, Varoqueaux F, Augustin I, Hesse D, Südhof TC, Takahashi M, Rosenmund C, Brose N (2002) $\beta$ Phorbol ester- and diacylglycerol-induced augmentation of transmitter release is mediated by munc13s and not by PKCs. Cell 108:121-133

Richards DA, Guatimosim C, Betz WJ (2000) Two endocytic recycling routes selectively fill two vesicle pools in frog motor nerve terminals. Neuron 27:551-559

Rios JC, Rubin M, St Martin M, Downey RT, Einheber S, Rosenbluth J, Levinson SR, Bhat M, Salzer JL (2003) Paranodal interactions regulate expression of sodium channel subtypes and provide a diffusion barrier for the node of Ranvier. J Neurosci 23:7001-7011

Roberts WM (1994) Localization of calcium signals by a mobile calcium buffer in frog saccular hair cells. J Neurosci 14:3246-3262

Robitaille R, Garcia ML, Kaczorowski GJ, Charlton MP (1993) Functional colocalization of calcium and calcium-gated potassium channels in control of transmitter release. Neuron 11:645-655

Rodríguez-Contreras A, Lange RPJ de, Lucassen PJ, Borst JGG (2006) Branching of calyceal afferents during postnatal development in the rat auditory brainstem. J Comp Neurol 496:214-228

Rowland KC, Irby NK, Spirou GA (2000) Specialized synapseassociated structures within the calyx of Held. J Neurosci 20:9135-9144

Royle SJ, Lagnado L (2003) Endocytosis at the synaptic terminal. J Physiol (Lond) 553:345-355

Rudy B, McBain CJ (2001) Kv3 channels: voltage-gated $\mathrm{K}^{+}$channels designed for high-frequency repetitive firing. Trends Neurosci 24:517-526

Ryugo DK, Wu MM, Pongstaporn T (1996) Activity-related features of synapse morphology: a study of endbulbs of Held. J Comp Neurol 365:141-158

Sahara Y, Takahashi T (2001) Quantal components of the excitatory postsynaptic currents at a rat central auditory synapse. J Physiol (Lond) 536:189-197

Saitoh N, Hori T, Takahashi T (2001) Activation of the epsilon isoform of protein kinase $\mathrm{C}$ in the mammalian nerve terminal. Proc Natl Acad Sci USA 98:14017-14021

Sakaba T (2006) Roles of the fast-releasing and the slowly releasing vesicles in synaptic transmission at the calyx of Held. J Neurosci 26:5863-5871

Sakaba T, Neher E (2001a) Quantitative relationship between transmitter release and calcium current at the calyx of Held synapse. J Neurosci 21:462-476

Sakaba T, Neher E (2001b) Calmodulin mediates rapid recruitment of fast-releasing synaptic vesicles at a calyx-type synapse. Neuron 32:1119-1131

Sakaba T, Neher E (2003) Direct modulation of synaptic vesicle priming by $\mathrm{GABAB}$ receptor activation at a glutamatergic synapse. Nature 424:775-778

Sakaba T, Stein A, Jahn R, Neher E (2005) Distinct kinetic changes in neurotransmitter release after SNARE protein cleavage. Science 309:491-494 
Sankaranarayanan S, Ryan TA (2000) Real-time measurements of vesicle-SNARE recycling in synapses of the central nervous system. Nat Cell Biol 2:197-204

Santoro B, Chen S, Luthi A, Pavlidis P, Shumyatsky GP, Tibbs GR, Siegelbaum SA (2000) Molecular and functional heterogeneity of hyperpolarization-activated pacemaker channels in the mouse CNS. J Neurosci 20:5264-5275

Sätzler K, Söhl LF, Bollmann JH, Borst JGG, Frotscher M, Sakmann B, Lübke JH (2002) Three-dimensional reconstruction of a calyx of Held and its postsynaptic principal neuron in the medial nucleus of the trapezoid body. J Neuroscience 22:10567-10579

Scheuss V, Neher E (2001) Estimating synaptic parameters from mean, variance and covariance in trains of synaptic responses. Biophys J 81:1970-1989

Scheuss V, Schneggenburger R, Neher E (2002) Separation of presynaptic and postsynaptic contributions to depression by covariance analysis of successive EPCSs at the calyx of Held synapse. J Neurosci 22:728-739

Schikorski T, Stevens CF (1997) Quantitative ultrastructural analysis of hippocampal excitatory synapses. J Neurosci 17:5858-5867

Schikorski T, Stevens CF (2001) Morphological correlates of functionally defined synaptic vesicle populations. Nat Neurosci 4:391-395

Schneggenburger R, Neher E (2000) Intracellular calcium dependence of transmitter release rates at a fast central synapse. Nature 406:889-893

Schneggenburger R, Neher E (2005) Presynaptic calcium and control of vesicle fusion. Curr Opin Neurobiol 15:266-274

Schneggenburger R, Meyer AC, Neher E (1999) Released fraction and total size of a pool of immediately available transmitter quanta at a calyx synapse. Neuron 23:399-409

Schoepp DD (2001) Unveiling the functions of presynaptic metabotropic glutamate receptors in the central nervous system. J Pharmacol Exp Ther 299:12-20

Shapira R, Silberberg SD, Ginsburg S, Rahamimoff R (1987) Activation of protein kinase $\mathrm{C}$ augments evoked transmitter release. Nature 325:58-60

Silver RA (2003) Estimation of nonuniform quantal parameters with multiple-probability fluctuation analysis: theory, application and limitations. J Neurosci Meth 130:127-141

Silver RA, Lübke J, Sakmann B, Feldmeyer D (2003) Highprobability uniquantal transmission at excitatory synapses in the barrel cortex. Science 302:1981-1984

Simon SM, Llinás RR (1985) Compartmentalization of the submembrane calcium activity during calcium influx and its significance in transmitter release. Biophys J 48:485-498

Sivaramakrishnan S, Laurent G (1995) Pharmacological characterization of presynaptic calcium currents underlying glutamatergic transmission in the avian auditory brainstem. J Neurosci 15:6576-6585

Smith PH, Joris PX, Carney LH, Yin TCT (1991) Projections of physiologically characterized globular bushy cell axons from the cochlear nucleus of the cat. J Comp Neurol 304:387-407

Smith AJ, Owens S, Forsythe ID (2000) Characterisation of inhibitory and excitatory postsynaptic currents of the rat medial superior olive. J Physiol (Lond) 529:681-698

Song P, Yang Y, Barnes-Davies M, Bhattacharjee A, Hamann M, Forsythe ID, Oliver DL, Kaczmarek LK (2005) Acoustic environment determines phosphorylation state of the Kv3.1 potassium channel in auditory neurons. Nat Neurosci 8: $1335-1342$

Sorensen JB (2004) Formation, stabilization and fusion of the readily releasable pool of secretory vesicles. Eur J Physiol 448:347-362

Southan AP, Robertson B (1998) Patch-clamp recordings from cerebellar basket cell bodies and their presynaptic terminals reveal an asymmetric distribution of voltage-gated potassium channels. J Neurosci 18:948-955

Southan AP, Morris NP, Stephens GJ, Robertson B (2000) Hyperpolarization-activated currents in presynaptic terminals of mouse cerebellar basket cells. J Physiol (Lond) 526:91-97

Spirou GA, Brownell WE, Zidnac M (1990) Recordings from cat trapezoid body and HRP labeling of globular bushy cell axons. J Neurophysiol 63:1169-1190

Stanley EF, Goping G (1991) Characterization of a calcium current in a vertebrate cholinergic presynaptic nerve terminal. J Neurosci 11:985-993

Südhof TC (2004) The synaptic vesicle cycle. Annu Rev Neurosci 27:509-547

Sun J-Y, Wu L-G (2001) Fast kinetics of exocytosis revealed by simultaneous measurements of presynaptic capacitance and postsynaptic currents at a central synapse. Neuron 30:171-182

Sun JY, Wu X-S, Wu L-G (2002) Single and multiple vesicle fusion induce different rates of endocytosis at a central synapse. Nature 417:555-559

Sun XP, Stanley EF (1996) An ATP-activated, ligand-gated ion channel on a cholinergic presynaptic nerve terminal. Proc Natl Acad Sci USA 93:1859-1863

Takago H, Nakamura Y, Takahashi T (2005) G protein-dependent presynaptic inhibition mediated by AMPA receptors at the calyx of Held. Proc Natl Acad Sci USA 102:7368-7373

Takahashi T, Forsythe ID, Tsujimoto T, Barnes-Davies M, Onodera K (1996) Presynaptic calcium current modulation by metabotropic glutamate receptor. Science 274:594-597

Takahashi T, Kajikawa Y, Tsujimoto T (1998) G-protein-coupled modulation of presynaptic calcium currents and transmitter release by a $\mathrm{GABA}_{\mathrm{B}}$ receptor. J Neurosci 18:3138-3146

Taschenberger $\mathrm{H}$, von Gersdorff $\mathrm{H}$ (2000) Fine-tuning an auditory synapse for speed and fidelity: developmental changes in presynaptic waveform, EPSC kinetics, and synaptic plasticity. J Neurosci 20:9162-9173

Taschenberger H, Leao RM, Rowland KC, Spirou GA, Gersdorff H von (2002) Optimizing synaptic architecture and efficiency for high-frequency transmission. Neuron 36:1127-1143

Taschenberger H, Scheuss V, Neher E (2005) Release kinetics, quantal parameters and their modulation during short-term depression at a developing CNS synapse in the rat. J Physiol (Lond) 568:513-537

Thorn PJ, Wang XM, Lemos JR (1991) A fast, transient $\mathrm{K}^{+}$current in neurohypophysial nerve terminals of the rat. J Physiol (Lond) 432:313-326

Tollin DJ (2003) The lateral superior olive: a functional role in sound source localization. Neuroscientist 9:127-143

Trommershäuser J, Schneggenburger R, Zippelius A, Neher E (2003) Heterogeneous presynaptic release-probabilities: functional relevance for short-term plasticity. Biophys J 84:1563-1579

Trussell LO (1999) Synaptic mechanisms for coding timing in auditory neurons. Annu Rev Physiol 61:477-496

Trussell LO, Zhang S, Raman IM (1993) Desensitization of AMPA receptors upon multiquantal neurotransmitter release. Neuron 10:1185-1196

Tsien JZ, Chen DF, Gerber D, Tom C, Mercer EH, Anderson DJ, Mayford M, Kandel ER, Tonegawa S (1996) Subregion-and cell type-restricted gene knockout in mouse brain. Cell $87: 1317-1326$

Tsujimoto T, Jeromin A, Saitoh N, Roder JC, Takahashi T (2002) Neuronal calcium sensor 1 and activity-dependent facilitation of P/Q-type calcium currents at presynaptic nerve terminals. Science 295:2276-2279

Turecek R, Trussell LO (2001) Presynaptic glycine receptors enhance transmitter release at a mammalian central synapse. Nature 411:587-590 
Turecek R, Trussell L (2002) Reciprocal developmental regulation of presynaptic ionotropic receptors. Proc Natl Acad Sci USA 99:13884-13889

Voets $\mathrm{T}$ (2000) Dissection of three $\mathrm{Ca}^{2+}$-dependent steps leading to secretion in chromaffin cells from mouse adrenal slices. Neuron 28:537-545

von Gersdorff H, Schneggenburger R, Weis S, Neher E (1997) Presynaptic depression at a calyx synapse: The small contribution of metabotropic glutamate receptors. J Neurosci 17: $8137-8146$

Wadiche JI, Jahr CE (2001) Multivesicular release at climbing fiberPurkinje cell synapses. Neuron 32:301-313

Walmsley B, Alvarez FJ, Fyffe REW (1998) Diversity of structure and function at mammalian central synapses. Trends Neurosci 21:81-88

Wang L-Y, Kaczmarek LK (1998) High-frequency firing helps replenish the readily releasable pool of synaptic vesicles. Nature 394:384-388

Wang H, Kunkel DD, Schwartzkroin PA, Tempel BL (1994) Localization of Kv1.1 and Kv1.2, two K channel proteins, to synaptic terminals, somata, and dendrites in the mouse brain. J Neurosci 14:4588-4599

Watano T, Calvert JA, Vial C, Forsythe ID, Evans RJ (2004) P2X receptor subtype-specific modulation of excitatory and inhibitory synaptic inputs in the rat brainstem. J Physiol (Lond) 558:745-757

Weis S, Schneggenburger R, Neher E (1999) Properties of a model of $\mathrm{Ca}^{++}$-dependent vesicle pool dynamics and short term synaptic depression. Biophys J 77:2418-2429

Wimmer VC, Nevian T, Kuner T (2004) Targeted in vivo expression of proteins in the calyx of Held. Pflugers Arch 449:319-333

Wimmer VC, Horstmann H, Groh A, Kuner T (2006) Donut-like topology of synaptic vesicles with a central cluster of mitochondria wrapped into membrane protrusions: a novel structure-function module of the adult calyx of Held. J Neurosci 26:109-116

Wölfel M, Schneggenburger R (2003) Presynaptic capacitance measurements and $\mathrm{Ca}^{2+}$ uncaging reveal submillisecond exocytosis kinetics and characterize the $\mathrm{Ca}^{2+}$ sensitivity of vesicle pool depletion at a fast CNS synapse. J Neuroscience 23:7059-7068

Wong AYC, Graham BP, Billups B, Forsythe ID (2003) Distinguishing between presynaptic and postsynaptic mechanisms of shortterm depression during action potential trains. J Neurosci 23:4868-4877
Wong AYC, Billups B, Evans RJ, Forsythe ID (2006) Endogenous activation of adenosine $\mathrm{A} 1$ receptors but not $\mathrm{P} 2 \mathrm{X}$ receptors during high frequency synaptic transmission at the calyx of Held. J Neurophysiol 95:3336-3342

Wu L-G, Borst JGG (1999) The reduced release probability of releasable vesicles during recovery from short-term synaptic depression. Neuron 23:821-832

Wu XS, Wu LG (2001) Protein kinase C increases the apparent affinity of the release machinery to $\mathrm{Ca}^{2+}$ by enhancing the release machinery downstream of the $\mathrm{Ca}^{2+}$ sensor. J Neurosci 21: 7928-7936

Wu LG, Westenbroek RE, Borst JGG, Catterall WA, Sakmann B (1999) Calcium channel types with distinct presynaptic localization couple differentially to transmitter release in single calyxtype synapses. J Neurosci 19:726-736

Wu W, Xu J, Wu X-S, Wu LG (2005) Activity-dependent acceleration of endocytosis at a central synapse. J Neurosci 25:11676-11683

Xu-Friedman MA, Harris KM, Regehr WG (2001) Three-dimensional comparison of ultrastructural characteristics at depressing and facilitating synapses onto cerebellar Purkinje cells. J Neurosci 21:6666-6672

$\mathrm{Xu}$ J, Wu LG (2005) The decrease in presynaptic calcium current is a major cause of short-term depression at a calyx-type synapse. Neuron 46:633-645

Yamada WM, Zucker RS (1992) Time course of transmitter release calculated from simulations of a calcium diffusion model. Biophys J 61:671-682

Yamashita T, Ishikawa T, Takahashi T (2003) Developmental increase in vesicular glutamate content does not cause saturation of AMPA receptors at the calyx of Held. J Neurosci 23:3633-3638

Yamashita T, Hige T, Takahashi T (2005) Vesicle endocytosis requires dynamin-dependent GTP hydrolysis at a fast CNS synapse. Science 307:124-127

Yang Y-M, Wang L-Y (2006) Amplitude and kinetics of action potential-evoked $\mathrm{Ca}^{2+}$ current and its efficacy in triggering transmitter release at the developing calyx of Held synapse. J Neurosci 26:5698-5708

Young JZ, Keynes R (2005) The functioning of the giant nerve fibres of the squid. 1938-J.Z. and the discovery of squid giant nerve fibres. J Exp Biol 208:179-180

Zhang S, Trussell LO (1994) A characterization of excitatory postsynaptic potentials in the avian nucleus magnocellularis. J Neurophysiol 72:705-718 